\title{
Thermal Energy Storage Materials (TESMs)—What Does It Take to Make Them Fly?
}

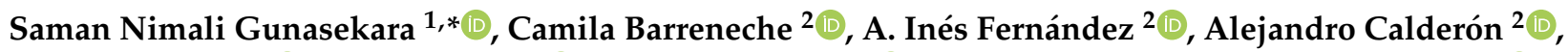

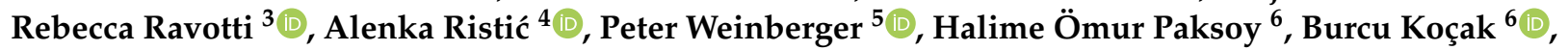 \\ Christoph Rathgeber ${ }^{7}$, Justin Ningwei Chiu ${ }^{1}\left({ }^{1}\right.$ and Anastasia Stamatiou ${ }^{3}\left[{ }^{\circledR}\right.$
}

1 Department of Energy Technology, KTH Royal Institute of Technology, Brinellvägen 68, 10044 Stockholm, Sweden; justin.chiu@energy.kth.se

2 Department of Materials Science \& Physical Chemistry, Universitat de Barcelona, Martí i Franquès, 1, 08028 Barcelona, Spain; c.barreneche@ub.edu (C.B.); ana_inesfernandez@ub.edu (A.I.F.); acalderon@ub.edu (A.C.)

3 Lucerne School of Engineering and Architecture, Institute of Mechanical Engineering and Energy Technology (IME), Technikumstrasse 21, Horw, 6048 Lucern, Switzerland; rebecca.ravotti@hslu.ch (R.R.); anastasia.stamatiou@hslu.ch (A.S.)

4 National Institute of Chemistry, Hajdrihova 19, SI-1001 Ljubljana, Slovenia; alenka.ristic@ki.si

5 Institute of Applied Synthetic Chemistry, TU Wien, Getreidemarkt 9, 1060 Vienna, Austria; peter.e163.weinberger@tuwien.ac.at

6 Chemistry Department, Faculty of Arts and Sciences, Çukurova University, Balcali Mah. Saricam, Adana 01310, Turkey; hopaksoy@cu.edu.tr (H.Ö.P.); kocakburcu@gmail.com (B.K.)

7 Bavarian Center for Applied Energy Research-ZAE Bayern, Walther-Meissner-Str. 6, 85748 Garching, Germany; christoph.rathgeber@zae-bayern.de

check for updates

Citation: Gunasekara, S.N.; Barreneche, C.; Inés Fernández, A.; Calderón, A.; Ravotti, R.; Ristić, A.; Weinberger, P.; Ömur Paksoy, H.; Koçak, B.; Rathgeber, C.; et al. Thermal Energy Storage Materials (TESMs) - What Does It Take to Make Them Fly? Crystals 2021, 11, 1276. https://doi.org/10.3390/cryst11111276

Academic Editor: Yifei Yuan

Received: 31 August 2021

Accepted: 14 October 2021

Published: 21 October 2021

Publisher's Note: MDPI stays neutral with regard to jurisdictional claims in published maps and institutional affiliations.

Copyright: (c) 2021 by the authors. Licensee MDPI, Basel, Switzerland. This article is an open access article distributed under the terms and conditions of the Creative Commons Attribution (CC BY) license (https:// creativecommons.org/licenses/by/ $4.0 /)$.
* Correspondence: sngu@kth.se; Tel.: +46-8-790-74-30

Abstract: Thermal Energy Storage Materials (TESMs) may be the missing link to the "carbon neutral future" of our dreams. TESMs already cater to many renewable heating, cooling and thermal management applications. However, many challenges remain in finding optimal TESMs for specific requirements. Here, we combine literature, a bibliometric analysis and our experiences to elaborate on the true potential of TESMs. This starts with the evolution, fundamentals, and categorization of TESMs: phase change materials (PCMs), thermochemical heat storage materials (TCMs) and sensible thermal energy storage materials (STESMs). PCMs are the most researched, followed by STESMs and TCMs. China, the European Union (EU), the USA, India and the UK lead TESM publications globally, with Spain, France, Germany, Italy and Sweden leading in the EU. Dissemination and communication gaps on TESMs appear to hinder their deployment. Salt hydrates, alkanes, fatty acids, polyols, and esters lead amongst PCMs. Salt hydrates, hydroxides, hydrides, carbonates, ammines and composites dominate TCMs. Besides water, ceramics, rocks and molten salts lead as STESMs for large-scale applications. We discuss TESMs' trends, gaps and barriers for commercialization, plus missing links from laboratory-to-applications. In conclusion, we present research paths and tasks to make these remarkable materials fly on the market by unveiling their potential to realize a carbon neutral future.

Keywords: thermal energy storage (TES); Thermal Energy Storage Materials (TESMs); sensible thermal energy storage materials (STESMs); phase change materials (PCMs); thermochemical heat storage materials (TCMs); carbon neutral future

\section{Introduction and Gaps in a Nutshell}

Energy storage is of paramount importance to realize the national, regional and global climate targets set to combat climate change. With more than $50 \%$ of global final energy demand being thermal [1], thermal energy storage (TES) is a compulsory element in today's energy systems. Besides, by adopting smart strategies such as power-to-heat [2,3] and power-to-cold [4], TES enables flexible coupling of electrical and thermal energy sectors [5], therefore encouraging an increased inclusion of renewables into the energy mix. 
Inherently, TES is achieved with numerous types of materials (TESMs), which are the focus of this article. TESMs include, yet are not limited to, thermophysical and thermochemical classes of materials [6], such as crystalline or amorphous materials as well as liquids (i.e., matter). These can be in the form of sensible TES materials (STESMs), latent heat TES (LHTES) using phase change materials (PCMs) (which are thermophysical materials) or thermochemical TES (TCS) using thermochemical heat storage materials (TCMs). Water is the most abundant, cheapest, most known and most used STESM and PCM, the latter is used in the form of ice [7]. Water to steam phase change is also used abundantly in energy applications; however, in this article, PCMs are considered per the most typical definition, only concerning solid-liquid phase change, thus excluding vapor-liquid phase change. For the case of solid-to-solid phase change (in TES), that is referred to as SSPCM. Although this work acknowledges the use of the term PCM also e.g., in the phase change memory alloys field (e.g., [8]), such fields outside TES are excluded here.

When the thermal applications' technical and economic conditions are satisfied by what water or ice can offer, these are the best choices that exist for TES. However, when the TES application temperatures, compactness, and/or flexibility in operating conditions (e.g., to allow temperature regulation or tailoring) surpasses the capabilities of water, other TES solutions are essential. There, STESMs, PCMs and TCMs beyond water/ice become attractive counterparts. Thus, the development of innovative TESMs has advanced in many research and development $(R \& D)$ projects over the past five decades. Today, sensible TES in low to medium temperatures $\left(\sim 0-200{ }^{\circ} \mathrm{C}\right)$ is dominated by water, rock, ceramics and similar, cost-effective and abundant materials. In the subzero region, certain oils and waterglycol mixtures dominate. For high temperature applications $\left(\sim\right.$ above $\left.200^{\circ} \mathrm{C}\right)$, especially in industries and power generation, STESMs are so far the most cost-effective option, resolving to, e.g., molten salts, rocks, and ceramics [9-11]. PCMs beyond ice comprise salt hydrates, paraffins, fatty acids and polyols as the most popular categories [7], while renewable organics [12], salts, and metal alloys are gaining momentum [13]. TCMs today are dominated by aluminophosphates, metal organic frameworks (MOFs), salt hydrates, metal oxides, zeolites and silica gel, while the reaction of salts with, e.g., ammonia has also gained reasonable momentum lately [14,15].

The aim of the R\&D has often been to design TESMs with high energy storage density and to test them in pilot installations under near-application conditions. However, in many cases it was apparent that the energy densities at storage- or system-level achieved in pilot installations could not approach the intrinsic material property values from material-level characterizations. Therefore, statements such as "this PCM/TCM has an x-times higher storage capacity than a hot water tank" cannot be always fulfilled in practice. For example, instead of an 8 or 10 times higher storage capacity (than sensible TES with water), the results at storage level under application conditions have been considerably lower [16], e.g., a factor of 3 [17]. This impedes the acquisition of subsequent projects and thus hinders further technology development. Together with other facts, this indicates that in order to elevate the technology readiness level (TRL) of TES and TESMs as technology enablers to large-scale commercialization, there are key missing pieces in the puzzle.

The general awareness of TES as a key energy storage technology (beyond electrical storage), and of TESMs as TES enablers (e.g., beyond water, rock, and molten salts) is inhomogeneous in society and even among scientific journals. A bibliometric study on LHTES in 2000-2019 [18] illustrates that the publications in materials-dedicated journals are only half of the highest number of publications in LHTES. These awareness and communication gaps create inconsistencies in material characterization standards, which result in data discrepancies, as often encountered and expressed within various literature reviews on the topic (e.g., [19-21]). Data discrepancies also give rise to unexpected/poorly predicted behaviors of the TES systems employing these TESMs, by experiencing mismatch between the intrinsic properties and application-scale behaviors. IEA SHC/ECES Tasks/Annexes on compact TES (Annex 24, 29 and T58A33, and the new T40T67) [22] have a long and fruitful history of the standardization of material characterization methods on TES, which 
also involve round-robin tests (RRTs). The country representation there is primarily Europe, and sometimes also from Japan, Canada, and the USA. Whereas, as [18] reveals, the LHTES publications by, e.g., China, surpass other countries by many-fold; however, with no representation in these standardization activities. This is also evidence of awareness and communication gaps in TES (here LHTES) as a research field. Even the societal awareness and acceptance of TES lags behind, impacting socio-cultural, policy and legal aspects essential for broader implementation of TES as seen in Spain [23], yet with commonalities applicable globally.

As the research on TCMs has often been conveyed by application-oriented groups without in-depth expertise in characterization techniques on the molecular and particle scale $[24,25]$ there is no unambiguous performance description of salt hydrates and metal oxides, confusing the TCM community in the last decades. On the other hand, mechanisms of water sorption on microporous aluminophosphate with LTA topology and chabazite topology have been studied with advanced structural characterization, explaining structureproperty relationships in detail in $[26,27]$. The gases adsorption on zeolites has been known even longer [28]. Similar to the standardization efforts by the PCM community, this lack of detail on chemical reactions of TCMs hampered the direct comparison of results, e.g., for the wide-spread investigations on the hydration of magnesium oxide [29].

As a whole, despite the numerous TES applications today, the large-scale commercial deployment of TESMs with their steadfast prospects to accomplish truly carbon neutral energy systems is still far from a reality. Here, standardization, fundamental comprehension, awareness, and dissemination, as well as socio-political drivers, all appear to have a role to play. In this context, in this article, we combine our own experiences, literature findings and a bibliometric analysis to critically analyze and discuss the current context of TESMs. The findings here are discussed for the trends as well as barriers for large-scale exploration of TESMs to their true potential and therein the proposals on how to truly make these materials fly on the market.

\subsection{Objectives and Scope}

The aim of this article is to critically discuss the current context of TESM R\&D and dissemination, and therein bring multifaceted recommendations to accelerate TESMs' commercialization for large-scale application. There, the objectives are to:

- Discuss the evolution of TESMs using historical milestones and background;

- Illustrate the current context of TESMs in terms of awareness, state-of-the-art, and trends via a bibliometric analysis combined with our own experience and literature;

- Identify and discuss the material and non-material challenges, barriers and missing links from fundamentals to applications, which are the likely reasons why TESMs are not flying on the market;

- Explain the gaps: why TES development is highly customized, what consequences this has for TES material development, and that the market success of compact TES is therefore still low;

- Identify and discuss the essential elements from a materials perspective to bring TES technologies to the market, i.e., to close the gaps;

- Propose the key actions that are crucial to make TES materials "fly" on the market.

The scope of this article is primarily on TES materials (and matter, i.e., liquids), including both experimental and numerical research and developments. This includes molecular, structural, thermal, physical, chemical, economical, social, and political aspects of relevance. TES components or systems are, however, excluded (unless indirectly discussed as relevant to TESMs).

\subsection{The 'How' and the Bibliometric Analysis}

This work is a compilation and critical discussion of decades of experience on TES and TESM research by the authors, with support from scientific literature as well as a 
bibliometric analysis. The specific methodology and the scope of the bibliometric analysis are as follows.

The bibliometric study was carried out concerning the materials to be used as thermal energy storage media (i.e., TESMs). Several main phrases were used, combined with certain exclusion and complementary phases to restrict the scope to TESMs, applied to the search engine in the Web of Science (WoS) database. The correlation of keywords included in the bibliographic search is listed in Table 1 (with the corresponding summary of the keyword search string used given in the Appendix A). This bibliometric analysis was performed using mathematical codes in the software Python, combined with graphical tools. There, for visualizing bibliometric networks, VOS viewer [30] was employed. This was supplemented with analyses from the Complexity Lab Barcelona software (CLabB) [31] for generating certain other analytics/diagrams. Only articles, reviews, book chapters and books are included in this search string. The search found 15,147 documents: 12,955 documents are classified as LHTES, 4696 documents are classified as sensible TES and 2374 documents classified as thermochemical TES. The detailed findings and their analysis are discussed in the ensuing sections.

Table 1. Keyword map used in the performed bibliometric study.

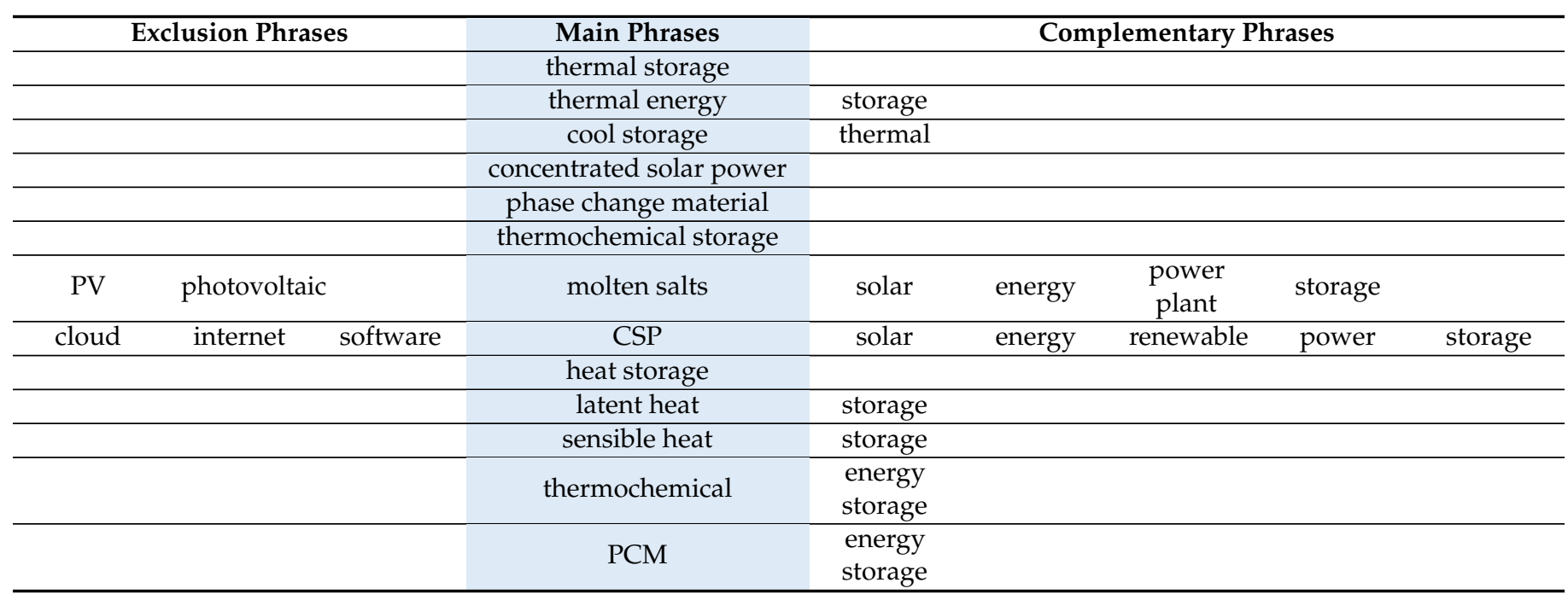

\subsection{Outline}

The main content of the article starts in Section 2. Sections 2.1-2.3 disclose the evolution and historical milestones of TESMs as well as the respective background on the three material types, PCMs, TCMs and STESMs* ( ${ }^{*}$ focusing on high-temperature types). The background here discusses the categorization of TESMs on each type as well as key fundamental aspects to better-comprehend the TES behavior of these materials and thereby to choose a robust TESM. Then follows Section 3, where the current state of TESMs is discussed. This constitutes a holistic discussion through the bibliometric analysis (Section 3.1) and then dwelling into specific trends and gaps these various TESM categories exhibit, by combining our experience with literature (Section 3.2). Section 3.2 comprises Sections $2.1-2.3$ on each respective material category, followed by Section 3.2.4 discussing their common trends. Section 3 ends with a critical discussion on the barriers and missing links from laboratory to application the TESMs experience (in Section 3.2.5). Finally, our concluding remarks are presented by means of critical discussions combined with suggestions on what should be done to truly make these remarkable materials fly on the market, to realize a truly carbon neutral future, in Section 4 . 


\section{History and Background}

TESMs have a long history, with the most conventional TESMs in STESMs such as water and rocks, and in LHTES in ice (and snow). To move forward and beyond, countless TESMs have paved the way to what TES is today, in all the three categories, STESMs, PCMs and TCMs. Here their historical milestones, categorization, and key fundamentals are concisely explored.

\subsection{STESMs-Evolution and Categorization}

Heat storage is an old practice using water reservoirs, water essentially being the most conventional and abundant STESM. Whereas, storing high-grade heat in solids also has interesting examples, such as the case of the raft furnace used as a forming glass furnace. This furnace incorporates, since the middle XIX century, a thermal regeneration system based on the use of two chambers, which operate alternately as heat exchangers, and each has a grid of refractory material, which is able to store thermal energy as sensible heat. As the hot gases pass through a chamber and cool the refractory material along the way, the combustion air enters through the other chamber preheated during its travel [32]. STESMs have also evolved beyond the traditional materials such as water and rocks, and can be generally categorized today as shown in Figure 1.
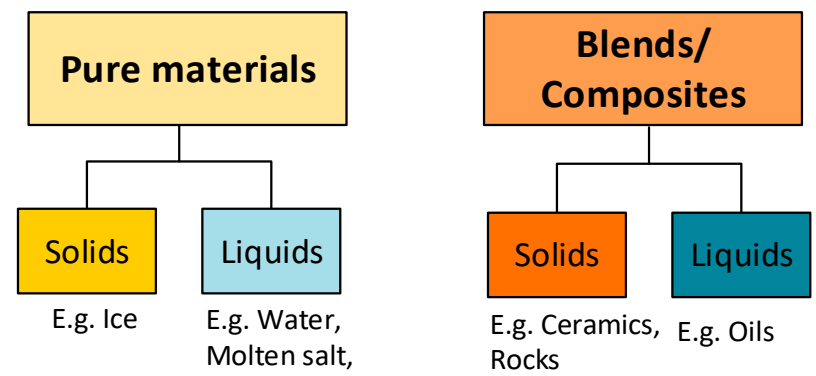

Figure 1. Basic categorization of STESMs.

Besides the typical space heating/cooling and insulation applications at low- to- moderate temperatures, a dominant and large-scale application of high-temperature STESMs is in CSP in terms of molten salts, rocks (e.g., granite), ceramics and metallic slag [33-36]. The key attraction with the STESMs is their relative simplicity in the material and therefore in TES applications, abundance, and lower costs. When the large-scale total cost wins over the volumetric energy storage density, STESMs have a clear competitive advantage over their other TES counterparts, i.e., PCMs and TCMs. Nevertheless, particularly the hightemperature STESMs require further R\&D to overcome their own set of challenges such as corrosion, and thermal stresses causing mechanical failures and poor cyclability [33-36] among others.

\subsection{PCMs—Evolution, Categorization and Key Fundamentals}

The earth and the sun provide the most abundant PCMs, ice and snow. Societies have been using ice and snow to preserve their food since ancient times. In Japan, Himuro tradition still celebrates the Ice House Festival on 1 June [37]. Natural ice was collected and stored in Himuro, an icehouse for use in summer. For the first time in hundreds of years this ice festival was cancelled for 2021. Even today, snow from the Taurus Mountains in southern Turkey packed behind trucks and covered with tents are sold in summer in Adana to be used for keeping food and drinks cold [37]. An age-old sensible TES practice has been employing the thermal mass of buildings (started off with rocks) for maintaining indoor thermal comfort.

The historical path of PCMs beyond ice and snow starts in the 1930s. The first materials used as modern PCMs consisted of low-cost, aqueous inorganic salt compounds (i.e., salt hydrates) that usually have freezing points below zero. Some of the first patented PCMs 
are from such salt hydrates, that consist of an inorganic salt with one or multiple water molecules, which dated back to the 1920s-1930s, with the first patent appearing in 1931 [38]. However, it was not until the 1940s that the concept of exploiting the latent heat of materials for energy storage purposes was introduced by Dr. Telkes [39]. Following this, NASA space program and other space programs carried out many PCM-based temperature control studies in the 1960s for different devices on the spaceships [37]. In addition, with the advent of the energy crisis in the late 1970s, TES became the focus of extensive research in solar heating systems [40]. Still, as the crisis subsided, the development and study of TES was subjected to a halt during the 1980s-1990s [41]. With the ambition of reaching new energetic and sustainable goals and with the definition of the Paris agreement [42], recently the focus has newly shifted to TES and latent heat storage systems [43]. Despite being the oldest of PCMs used for latent heat storage purposes, salt hydrates are characterized by a number of unsolved challenges, above all their tendency to phase separate. At present, this is mostly tackled by trying to use thickening agents that were proposed by Dr. Telkes in 1946 [37]. However, the phase separation of salt hydrates remains poorly understood $[43,44]$.

Besides salt hydrates, a multitude of PCMs, of both inorganic and organic origin, are investigated today. A majority of pure materials (i.e., an unary system/a single component) and binary material blends (i.e., fabricated of two components) are analyzed, followed by multicomponent blends $[7,12,45]$. The categorization of PCMs along the origin is depicted in Figure 2. Organic PCMs can be, e.g., alkanes (e.g., paraffins), alkenes, fatty acids, polyols (i.e., poly-alcohols or some even called sugar alcohols), alkanols, and in certain cases hydrates of these organics (e.g., pinacone hexahydrate). Inorganics are mainly based on salts (pure salts, salt blends, and salt hydrates) and metals (pure metals or metal alloys) $[7,12,45]$. The combination of organics and inorganics are not so common, yet this is also emerging [12]. Clathrates are another category of PCMs with only minor attention in TES so far. A clathrate is a single phase solid fabricated of two components, where the host crystal structure encloses the guest (often a gas) molecules [46]. Clathrates are not categorized as purely organic or inorganic [7] however, it appears to mostly originate from organics [46]. In Figure 2, clathrates can be placed within blends.

Pure material PCMs have a more straightforward phase change, however, high purity comes at a cost, particularly if they lack a large-scale market. Whereas, multicomponent blends become interesting options for adjusting the melting temperature to meet the application requirements, and/or, if they can be recovered within industrial by-products or within naturally abundant materials. However, blends come with inherent complexities. One cannot use just any blend composition as a PCM, it must be chosen carefully, always consulting the blend phase diagram.
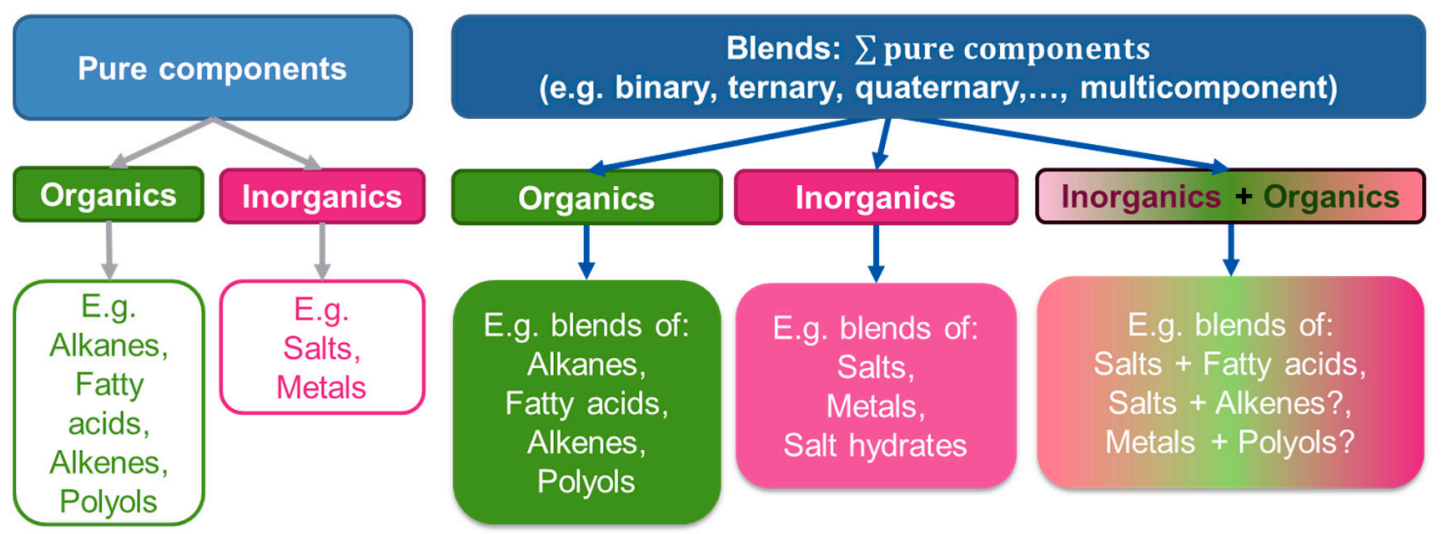

Figure 2. Categories of PCMs based on their origin and number of components (i.e., unary, binary, ternary, onwards up to multicomponent blends).

Here, congruent melting compositions (forming congruent melting solid solutions or congruent melting compounds) are the most suitable as PCMs in blends (Note: congruent 
melting, by definition, is when all phases (solid and liquid) in equilibrium have the same composition [38]. Congruent melting (and freezing) occurs in a very narrow temperature range involving components of the same composition and therefore same density, thus with no phase separation even with supercooling. Whereas, incongruently melting compositions contain phases of different compositions, causing phase separation), because they do not phase separate, even upon supercooling. (Note: a liquid cooled below the freezing point without crystallizing is called a supercooled melt, c.f. [47]). Eutectic blends are also suitable, as long as they do not supercool. Conversely, supercooling eutectics always phase separate. (Note: eutectics are not congruent melting by definition $[38,48]$. However, as the eutectics form an intimate mix of the solid components/phases with their combined composition equal to the liquid in equilibrium, thus act similar to congruent melting if supercooling is absent [38]). Incongruent melting compositions (including many peritectics) are recommended to be avoided in use as PCMs, as they always supercool and phase separate [38]. (Note: peritectics inherently undergo both supercooling and phase separation, and do not undergo complete transformation as they are metastable phases [38]. Thus, a peritectic is a poor PCM choice as it recombines less and less material at each consecutive cycle; hence, lowering the storage density at each cycle). The foremost reason for phase separation experienced in many salt hydrates is that they have peritectic compositions. Albeit much TES research and even certain applications (e.g., hand warmers) already use certain peritectics that supercool, these require copious efforts to achieve a rather satisfactory robustness, or simply fail after a certain number of cycles [49].

Indeed, in certain TES applications, some incongruent compositions which are yet rather close to being congruent, categorized as semi-congruent compositions [50], are found to function rather well, combined with measures to minimize incongruent effects at material and/or storage level. Nonetheless, the best approach is to simply avoid incongruent melting compositions as PCMs (for the extra efforts and costs needed and the uncertainties involved in their long-term robustness), in the search of robust PCMs. Again, looking at the popularity of salt hydrates, being attractive for their relative abundance and low cost, efforts are best concentrated on their congruent melting compounds or non-supercooling eutectics instead of the peritectics. The potential in salt hydrates is clearly very large, as seen in Figure 3. Similarly, a great unrealized potential remains in thoroughly exploiting congruent melting compositions in all material categories [12].

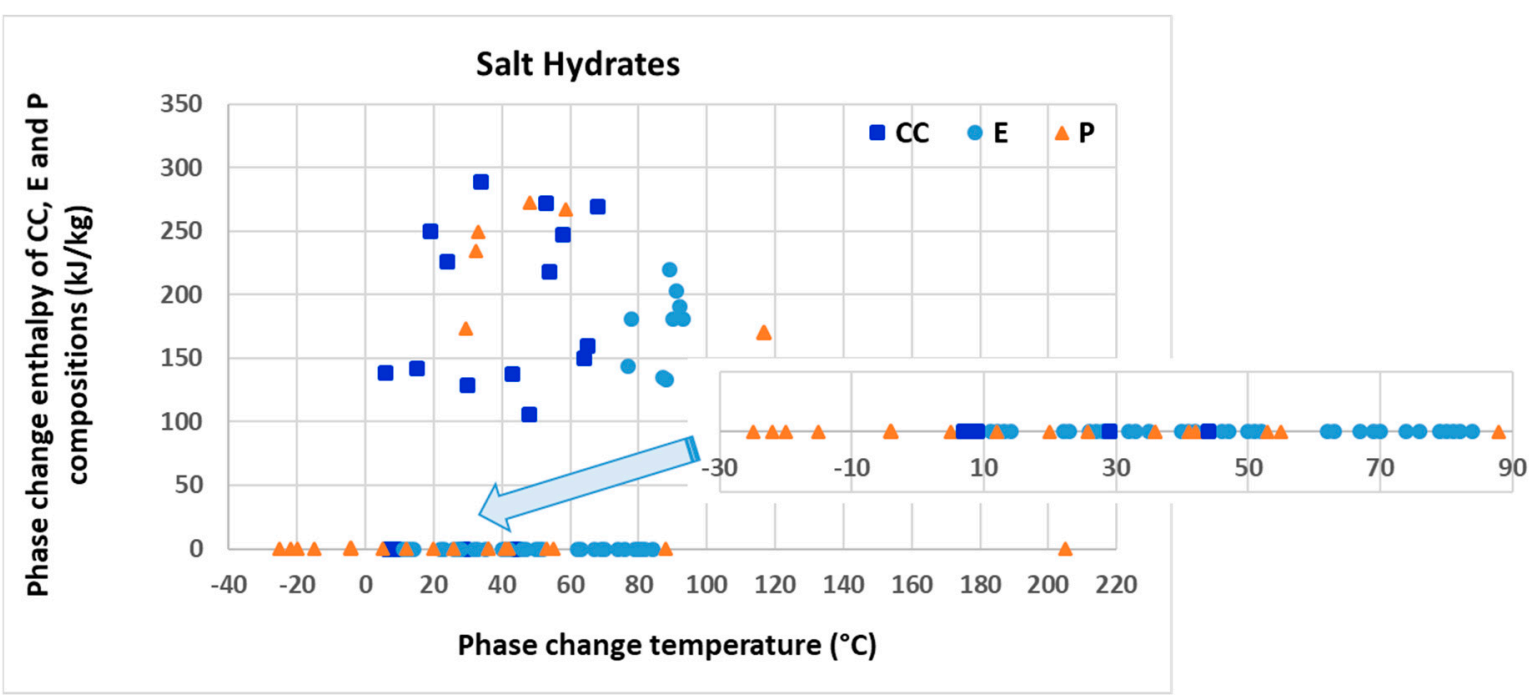

Figure 3. The congruent melting compounds (CC), eutectics (E) and peritectics (P) found within salt hydrates explored over four decades (1977-2016), mapped with phase change enthalpies (shown as zero when the data were unavailable) and temperatures (adapted from [49]).

For TES with PCMs, supercooling can be desired or undesired, depending on the application. Supercooling is a problem if the absence of crystallization makes regeneration 
(solidification) of the PCM impossible under the application conditions [47]. Besides, supercooling can be associated with exergetic losses during solidification and causes phase separation if the PCM chosen is an incongruently melting composition, therefore becoming undesirable. On the other hand, supercooling can be exploited for long-term TES. To trigger crystallization of the supercooled PCM, various methods exist, such as a local temperature reduction in the PCM to locally overcome the crystallization inhibition or the seeding of the liquid with solid crystals [47].

Since 2009, a joint working group of the technical collaboration programs (TCPs) solar heating and cooling (SHC) and the energy storage (ECES) within the International Energy Agency (IEA) has been working on compact Thermal Energy Storage materials and systems using PCMs and TCMs. The overall goal is to support applications-oriented development of PCMs and TCMs. This includes, first, the characterization of a new material concerning its properties such as heat of fusion or heat of reaction/sorption, specific heat, thermal conductivity, among others. In the second step, the material must be tested under reference application conditions. These conditions should be identified for energy relevant applications in a separate approach. The third step focuses on the interaction between the storage material and the storage component, and mainly with the heat and mass transfer achieved in the component or reactor. Thereby, the first results towards reliable power and energy density characteristics of the TES application can be deduced [22]. As a result, significant progress has been made in the understanding of compact heat storage materials and systems, and a strong basis for collaboration between experts in both materials science and system applications from a large number of countries has been established.

\subsection{TCMs-Evolution and Categorization}

The developments in TCMs are more recent; yet, they are gaining momentum today. TCMs can be categorized as shown in Figure 4 .

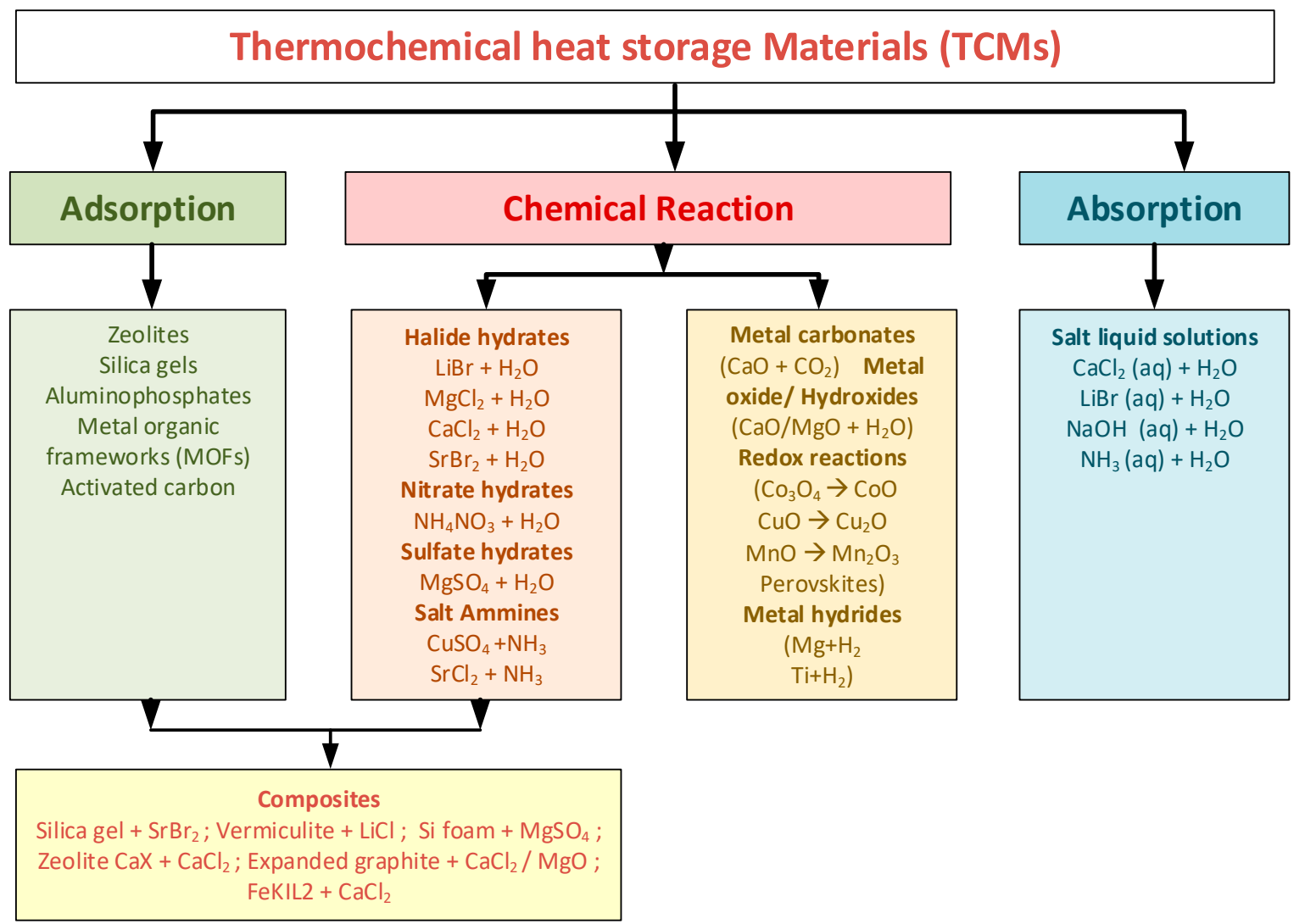

Figure 4. Thermochemical heat storage materials (TCMs) categorization based on the type of interaction: adsorption, chemical reaction or absorption. 
The classical TCMs are based on reversible solid-gas (or fluid) interactions with easyto-handle gases such as air/oxygen, water vapor, carbon dioxide or ammonia. These interactions primarily involve adsorption (i.e., physisorption, a sorption process only on the surface of the solid adsorbent), chemical reaction (i.e., chemisorption of a fluid into the entire bulk of the solid reactant molecules) or absorption (e.g., water absorption into aqueous salt solutions, also involving the molecules in their entirety). Adsorption and chemical reaction categories employ solid sorbents with fluid (liquid or gas) sorbates, whereas the absorption category involves both the sorbent and sorbate in a liquid state. Producing TCM composites by combining adsorption and chemical reaction categories is also an emerging practice.

Adsorption-based TCMs involve reversible sorption of gases (mainly water, but also ethanol, methanol, and ammonia) on porous adsorbents under aerobic or anaerobic conditions. The most investigated examples (c.f. Figure 4) are zeolites and silica gels, followed by others such as aluminophosphates, MOFs and activated carbons. Clays are used sometimes as adsorbent (salts) confinement media, while activated alumina, graphite, expanded graphite or multiwall carbon nanotubes are used for thermal conductivity enhancement and at times also for sorbent confinement. The TCMs involving chemical reactions predominantly include: hydration [51] or ammoniation ([14,52]) of anhydrous salts; between oxides and carbon dioxide to carbonates ([53-55]), between oxides and water vapor to hydroxides $([24,25,29,56])$, hydrides $([57,58])$ or redox reactions of redox-active metals $([59,60])$. The most investigated examples of water-based chemical reaction TCMs include, hydrates: e.g., $\mathrm{MgCl}_{2}, \mathrm{CaCl}_{2}, \mathrm{MgSO}_{4}, \mathrm{SrBr}_{2}, \mathrm{Na}_{2} \mathrm{~S}, \mathrm{NaOH}, \mathrm{LiBr}$, and $\mathrm{Al}_{2}\left(\mathrm{SO}_{4}\right)_{3}$; hydroxides: e.g., $\mathrm{Ca}(\mathrm{OH})_{2} / \mathrm{CaO}$ [61] and hydrides: e.g., $\mathrm{TiH}_{2} / \mathrm{TiO}, \mathrm{MgH}_{2} / \mathrm{TiO}$ and $\mathrm{CaH}_{2} / \mathrm{CaO}$ [58]. Those that react with $\mathrm{NH}_{3}$ (forming ammines, sometimes also referred to as ammoniates) include alkaline metal halides (a specific branch of salts) such as, e.g., $\mathrm{SrCl}_{2}, \mathrm{CaCl}_{2}, \mathrm{BaCl}_{2}, \mathrm{MgCl}_{2}$, and $\mathrm{NH}_{4} \mathrm{Cl}[61]$.

The water-based reactions (e.g., hydrates, hydroxides, hydrides) have gained the most attention so far, primarily owing to the ease of system design and operation as water is a safe material. Nonetheless, e.g., ammines and redox reactions as well as the composites are also gaining momentum, e.g., for their larger energy storage densities and/or better heat transfer aspects. Lately, significant attention has been paid to another class of TCM materials, i.e., composites (combining adsorption and chemical reaction materials), which are composed of porous solids or polymers acting as matrices for the homogeneous dispersion of the adsorption or chemical reaction salts or oxides. Absorption, comprising liquid salt solutions, also has considerable attention already as TCMs.

From a thermodynamic point of view, a myriad of sorption compound pairs is possible, as, e.g., an algorithm-based search yields [62]. However, the experimental outcomes of many such predicted candidates were disappointing, because the reaction kinetics are poorly understood due to their complexities on molecular and particle scales. There are rare cases of ideally reversible reactions [51], but in most cases the material suffers from decreasing reversibility due to irreversible crystallographic phase transitions under certain conditions (as found in, e.g., lead oxide between the massicot and litharge modification) or particle sintering. Severe changes in the compound structure on the crystallographic level can obstruct a reaction due to the formation of a particle covering layer blocking any further diffusion of the reactive gas. Sometimes the reaction conditions can be tuned to crack this protective layer to achieve reaction completion. However, this behavior requires tedious investigation and the insights are rarely transferable to another compound. This non-transferability of insights gained on a certain material towards other TCMs seems to be one major reason for the slow overall progress in making TCMs fly on the market as a versatile and easy-to-implement energy solution. As this is an intrinsic challenge, only when a match of industrial needs and a "well-behaving" TCM occurs, a development until TRL 9 is foreseeable.

Zeolites for sorption thermal energy storage are one of the few examples of TCM that have been investigated and developed along the entire length of TRLs. This includes 
fundamental research on zeolites at the molecular level, experimental measurements and simulations of the water adsorption capacity and adsorption enthalpy of pelletized zeolites as well as the design and optimization of zeolite fixed beds for energy relevant applications. The development and production of zeolite pellets for energy applications is carried out in close cooperation between industry and research entities. Examples of applications for TES with zeolite are: dishwashers with efficient sorptive drying (TRL 9) (commercialized by Bosch Siemens Hausgeräte since 2008) [63], a mobile sorption heat storage system for waste heat utilization in a waste incineration plant (TRL 7) [64], and adsorption heat pumps or chillers (TRL 9) [65].

\section{TESMs Today? Trends, Gaps, Barriers and Missing Links}

Despite decades of R\&D on TESMs, it is discernible that there remains an abundance of challenges in all three categories. Above all, large-scale commercialization of TES as a technology, and TESMs as the enablers of this technology, have not reached full maturity yet. This calls for a critical exploration of the causes that hinder their advancement. Therefore, here, the current state of TESMs, concerning PCMs, TCMs and STESMs are discussed concisely yet more specifically, also along their trends and gaps apparent today as well as the existing barriers to their exploration and growth. This includes the materialintrinsic aspects but also other facets such as awareness, dissemination and socio-politics. By synthesis of these findings, the essential steps and considerations are then discussed and proposed as recommendations to really make TESMs fly on the market, for small- to large-scale TES applications to truly realize carbon-neutral energy systems.

\subsection{A Holistic View}

The performed bibliometric study represents a holistic view on a multitude of avenues that are primordial to make TESMs truly fly on the market, and show several trends as well as gaps, concerning scientific dissemination, awareness and even collaborations. The evolution of the number of publications and citations concerning TESMs over the last three decades has been exponential, as seen in Figure 5. Although during the last three years the citation trend decreases drastically, this is only a temporary effect. That is, these recent publications are comparatively new, and hence will need more time to follow the same trend of those earlier publications. The evolution of TESMs publications classified by the TES technology used (thermochemical, i.e., TCMs, sensible, i.e., STESMs, or latent heat, i.e., PCMs) is shown in Figure 6. The technology with the most publications is LHTES, followed by sensible TES, and thermochemical TES. This trend is as expected, making LHTES a favorite for allowing a compromise between quite high TES capacity (yet not as high as TCMs) and a moderate level of technical challenges and system complexity (yet more challenging and complex than STES).

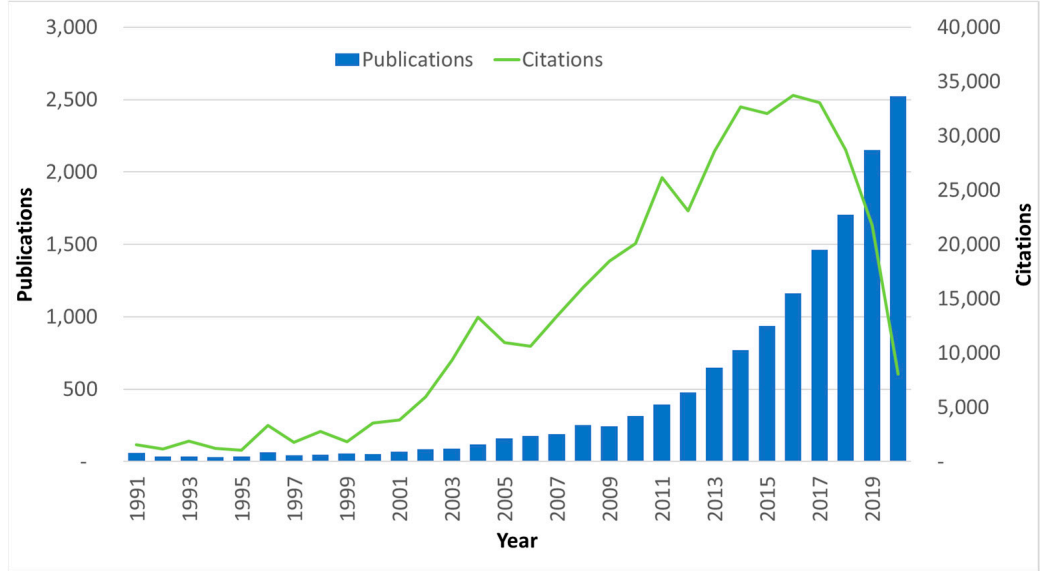

Figure 5. TES materials publications evolution and the citations evolution over the last three decades. 


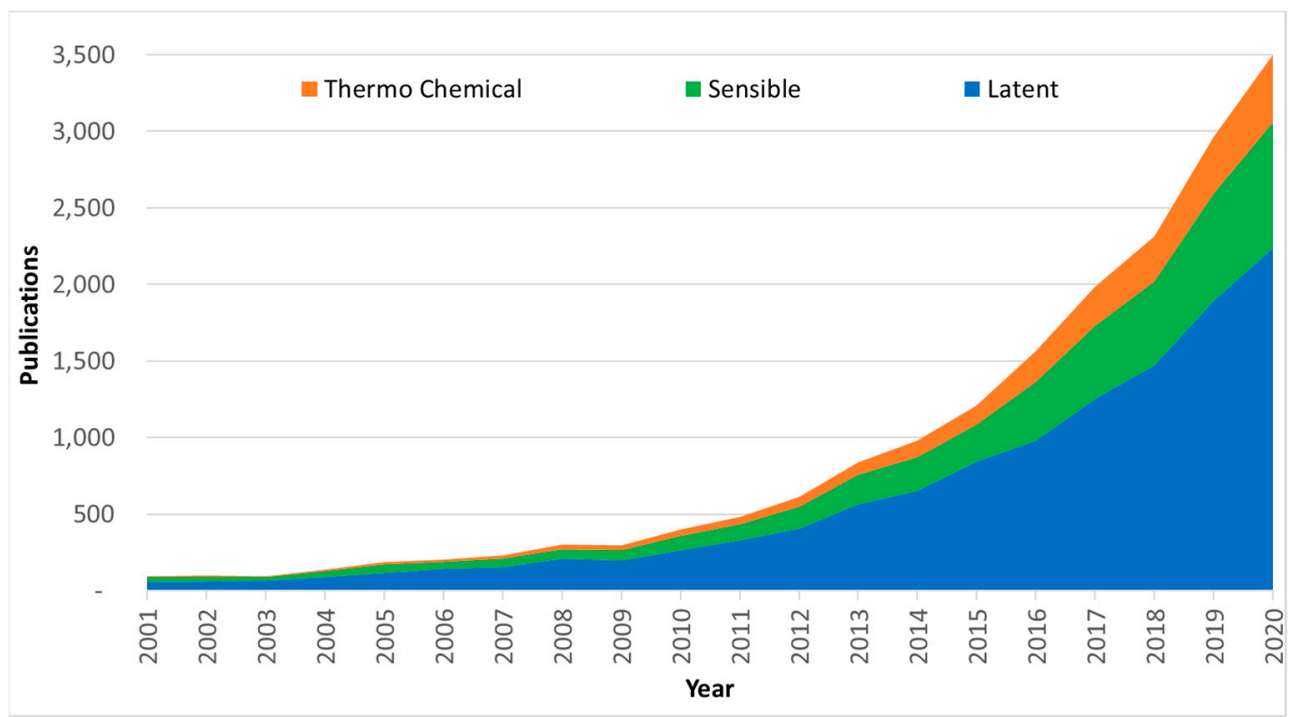

Figure 6. Publications evolution classified per thermal energy storage technology types, over the last two decades.

The country-specific representation of TESM publications is shown in Figures 7 and 8, on publishing in the TESMs field during the last two decades. Figure 7 presents the global top 20 countries with the European Union (EU) as one aggregate; whereas, Figure 8 presents the top 20 EU countries.

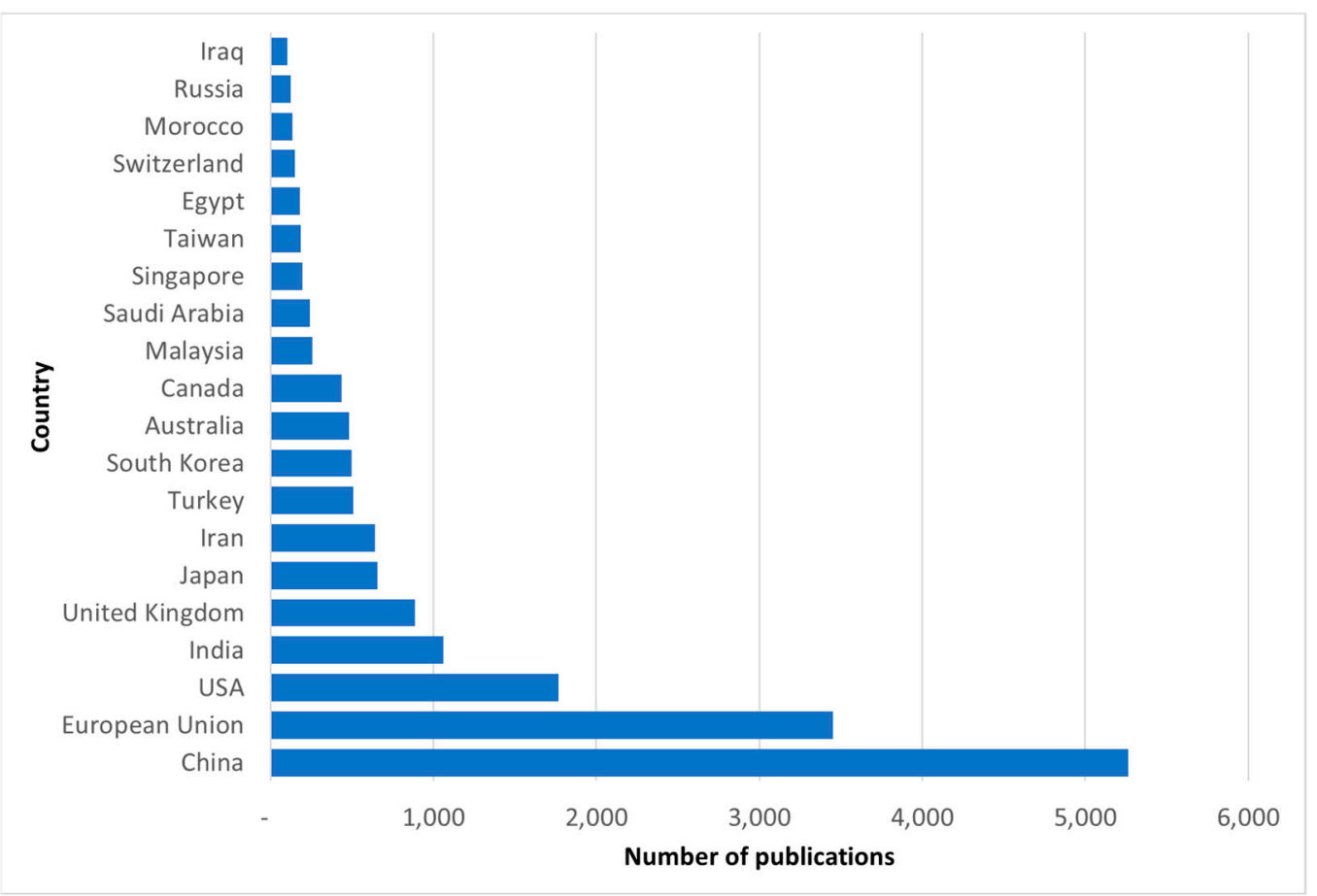

Figure 7. The number of publications in the field of TES materials field by country, with EU as a single category. 


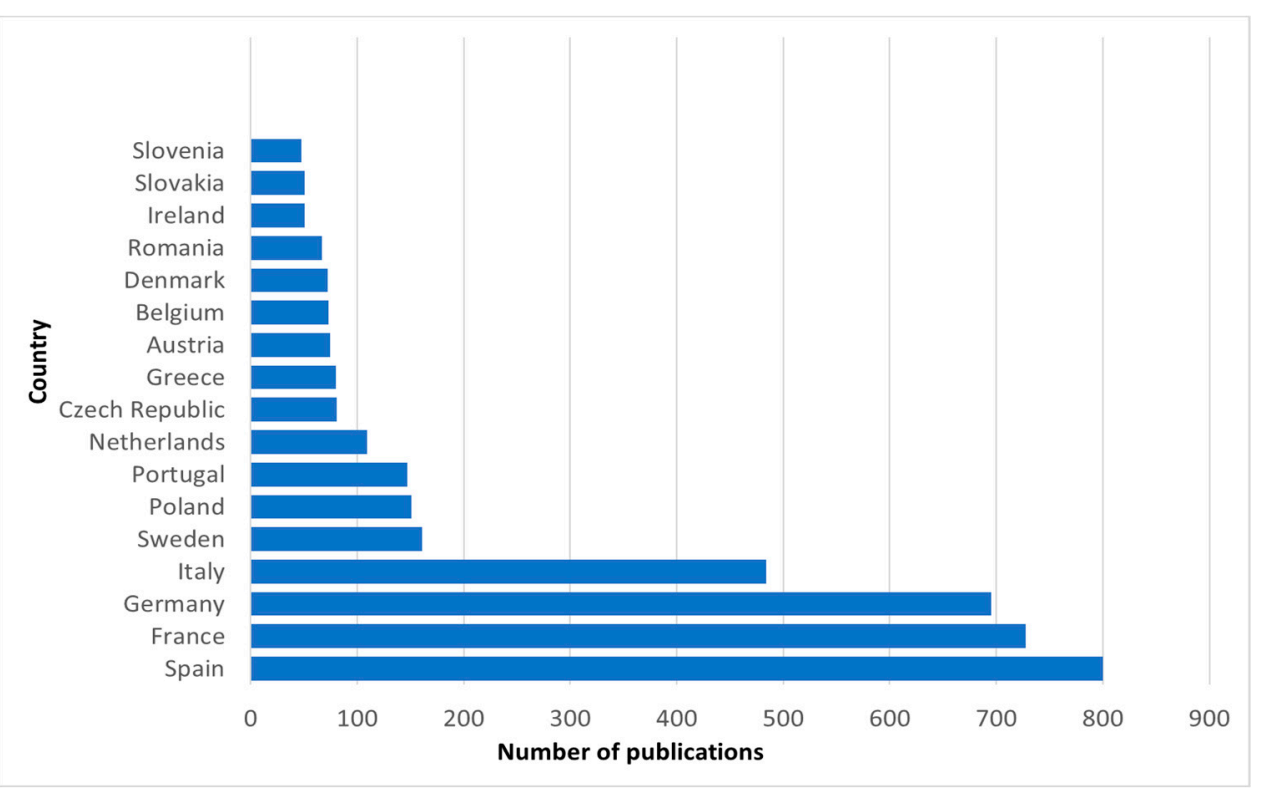

Figure 8. The number of publications in the field of TES materials field by country, just within EU.

As seen in Figure 7, the global top 20 that account for the highest number of publications comprise China ( $>5000$ publications), followed by the EU countries ( $\sim 3500$ publications), and the USA ( 1800 publications) during the last two decades. India and the UK are the next countries in the ranking followed by Japan, Iran, Turkey, South Korea, and Australia. Figure 8 shows that Spain leads in the EU with the highest number of publications (800) and citations $(26,000)$ concerning the development and characterization of TESMs. The performance ratio PR is used in this analysis as a metric of journal productivity (total citations in a research field divided by total research field publications). This metric has limitations, for example review journals have higher PRs, it provides a metric for the whole period evaluated instead of the impact factor indicator for the last 2 or 5 years. The performance ratio (PR) (is a productivity metric which results from dividing the total number of citations by the total of articles of each journal) for Spain is 33.54. Spain is followed by France with 728 publications, more than 21,000 citations and a PR of 29.17. The rest of the top 5 countries are Germany, Italy, and Sweden. These country-specific bibliometric overviews imply the popularity, awareness and the level of funding on these topics in different countries and regions, and therein indirectly the role of TES technology in the country- and region-specific agenda. Comprehensively assessing this, however, requires a complex investigation beyond the scope of this current work, which is impacted by, e.g., population and the development status of the countries and regions, which are diverse.

The level of networking and collaborations between researchers on the TESM field today are summed concerning the countries with the highest incidence of interactions in Figure 9 (for the global context with EU in an aggregate) and in Figure 10 (on the EU breakdown). Here, different colors represent different communities/countries and lines indicate the interaction between them. The larger the circle is, the higher the number of publications is, and the thicker the line is, the stronger the interactions are. 


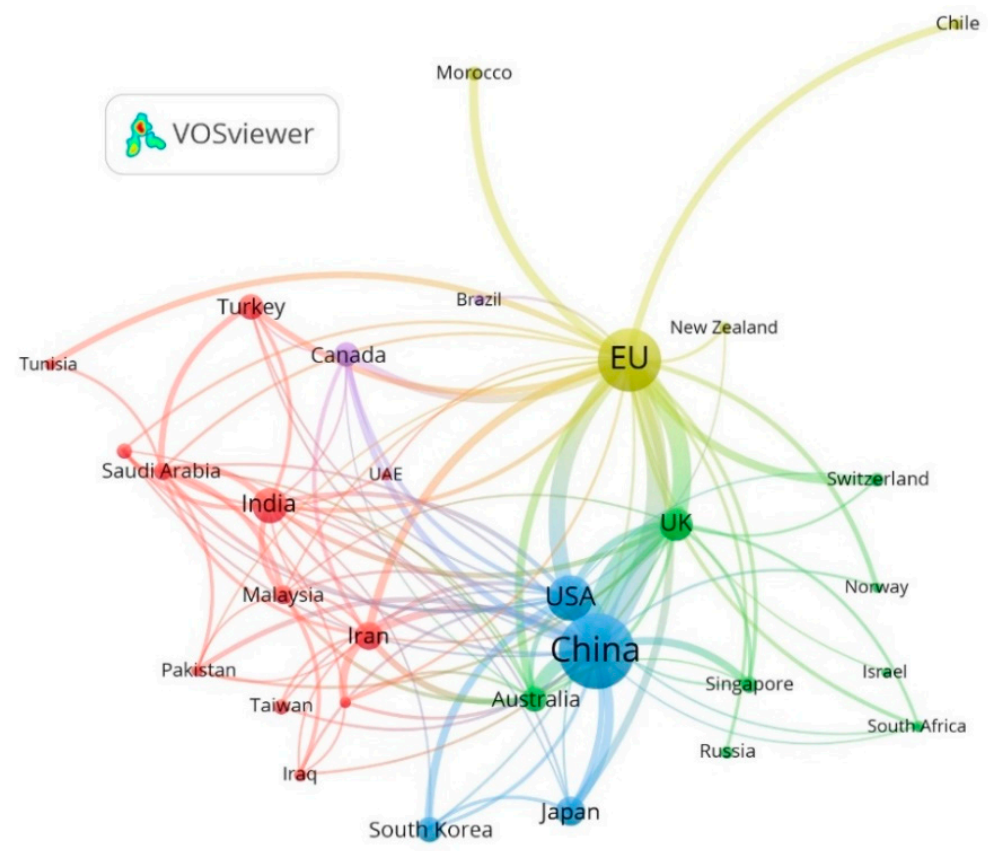

Figure 9. The country-specific co-authorship interaction-collaboration as seen within the top 20 collaboration countries.

The country-specific interaction in Figure 9 follows the same overall trend in Figure 7, e.g., where China, the EU, the USA, India and the United Kingdom (UK) (in the descending order) govern the majority. This dominance, however, does not exactly coincide with the IEA TCP activities (such as with SHC and ECES [22]) on standardization efforts on, e.g., TESM characterization methods. These IEA TCP activities (and individual entities such as RAL [66] on commercial PCMs' standardization) involve a majority of the EU plus, e.g., East Asia (e.g., Japan and sometimes Korea), the USA and Canada. An integration and inclusion of such IEA activities into these dominant research contributors (but not limited to) who are so far outside the spheres of the IEA and is a key missing piece as these findings exhibit. For this inclusion, the countries must be members of the IEA TCP activities, which thus necessitates the promotion and dissemination of these activities into non-member countries' socio-political agendas. Expanding these IEA TCP and similar activities globally, to have a homogeneous and sufficient representation of all vital actors, is a deterministic step in unifying the material characterizations and data that are published. This is a key step to achieve data consistency and thereby reliable predictions of TESMs and their behavior in TES applications.

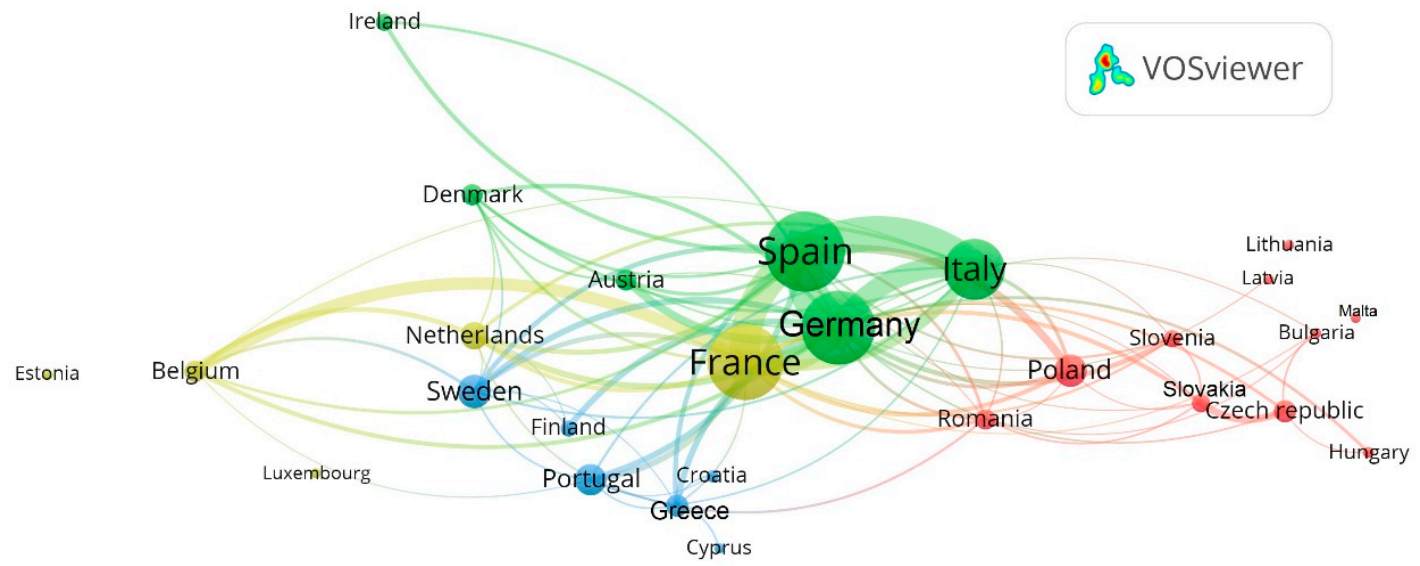

Figure 10. The country co-authorship interaction collaboration of the top 20 European Union countries. 
Concerning the TESM research interactions within the EU as in Figure 11, the strongest TESM research interactions are observed between France, Spain, Italy, and Germany. Four main interaction communities can be also identified, enclosed in green, red, blue, and yellow. One of these communities (in green) consists of Spain, Germany, Italy, Austria, Denmark and Ireland. Another (denoted in red) constitutes of the countries such as Poland, Romania, Czech Republic, Slovakia Slovenia, Hungary, Lithuania, and Bulgaria. The blue interaction group encompasses, e.g., Portugal, Sweden, Greece, Finland, Croatia, and Cyprus. Another is found, involving (in yellow), e.g., France, the Netherlands, Belgium and Estonia. The interactions are a positive indication of joining forces whereas there is always room for improvement, and for stronger and wider networking. The EU-level dedicated funding programs have been the backbone to establish these strong networks and collaborations, while other regional and country-specific funding authorities prove to be strong complements, e.g., to strengthen regional collaborations.

In the bibliometric study, the main journals where the researchers are publishing their advances on TESMs are also reviewed. Figure 10 shows the top 20 indexed research areas selected by the research communities to disseminate their scientific progress regarding TESMs' development in the last 5 years. The most preferred areas are energy and fuels ( $>6000$ publications), followed by engineering ( $>4800$ publications), thermodynamics (>3500 publications), materials science ( $>3100$ publications), and chemistry ( $>2500$ publications). Interestingly, for a field that is inherently focused on materials, the research area on materials is only half as popular as the broader and an applied scope such as energy and fuels.

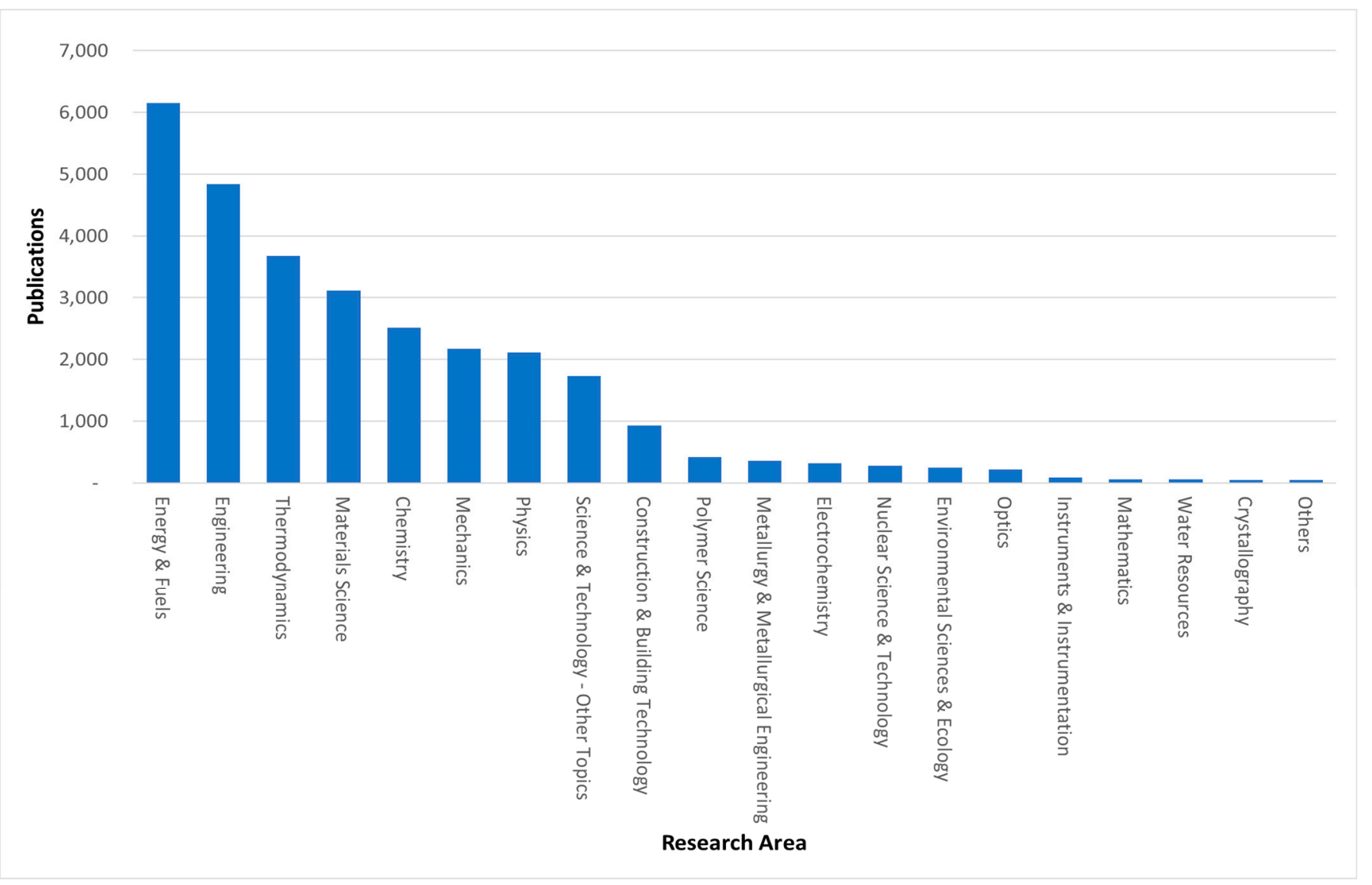

Figure 11. Indexed research areas preferred by the research community to publish their advances in materials for TES field considering the last 5 years publications.

Table 2 is exemplary evidence of the dissemination trends but also the gaps concerning TESM in publications within scientific journals. Clearly, journals dedicated to applied research 
dominate with the most TESMs publications and citations, while the journals dedicated to materials (and fundamental) research are lagging. The bright side is that then the fundamental TESM research reaches a broader audience, including the applied TES community who uses these results in TES applications design. However, Table 2 is also an indication of an awareness (and perhaps also an acceptance) gap within the scientific journals devoted to fundamental material research in identifying the relevance and importance of TESM. This is just the tip of the iceberg, which suggests that TESM research has a long journey ahead to surpass these gaps via dissemination also beyond scientific publications and to position itself as an equal amongst other energy storage counterparts.

Table 2. Scientific dissemination of TESM over the last two decades, the top 20 journals (with the most publications) on the scope of TES and TESM, with the number of papers, citations and performance ratio (PR).

\begin{tabular}{|c|c|c|c|c|c|c|c|}
\hline TES Journal & Papers & Citations & PR & TES Materials-Related Journal & Papers & Citations & PR \\
\hline Applied Thermal Engineering & 910 & 28,403 & 31 & Solar Energy Materials And Solar Cells & 521 & 21,356 & 41 \\
\hline Applied Energy & 648 & 31,645 & 49 & Thermochimica Acta & 206 & 6229 & 30 \\
\hline Solar Energy & 547 & 20,497 & 37 & $\begin{array}{l}\text { Journal Of Thermal Analysis And } \\
\text { Calorimetry }\end{array}$ & 201 & 2942 & 15 \\
\hline Solar Energy Materials And Solar Cells & 521 & 21,356 & 41 & Construction And Building Materials & 131 & 2132 & 16 \\
\hline Energy Conversion And Management & 486 & 24,668 & 51 & Journal Of Applied Polymer Science & 97 & 2222 & 23 \\
\hline Energy And Buildings & 474 & 19,723 & 42 & Applied Physics Letters & 96 & 2819 & 29 \\
\hline $\begin{array}{l}\text { International Journal of Heat And Mass } \\
\text { Transfer }\end{array}$ & 445 & 16,654 & 37 & Materials & 92 & 868 & 9 \\
\hline Energy & 362 & 10,628 & 29 & Journal Of Materials Chemistry A & 90 & 3200 & 36 \\
\hline Renewable Energy & 337 & 10,135 & 30 & Acs Applied Materials E Interfaces & 89 & 1959 & 22 \\
\hline Journal Of Energy Storage & 335 & 2633 & 8 & Journal Of Molecular Liquids & 76 & 1510 & 20 \\
\hline Renewable E Sustainable Energy Reviews & 261 & 31,933 & 122 & Journal Of Applied Physics & 70 & 1907 & 27 \\
\hline International Journal Of Energy Research & 231 & 3556 & 15 & Journal Of Physical Chemistry C & 57 & 1571 & 28 \\
\hline Thermochimica Acta & 206 & 6229 & 30 & Journal Of Alloys And Compounds & 51 & 1413 & 28 \\
\hline Energies & 202 & 1311 & 6 & Materials Research Express & 47 & 187 & 4 \\
\hline $\begin{array}{l}\text { Journal Of Thermal Analysis And } \\
\text { Calorimetry }\end{array}$ & 201 & 2942 & 15 & Materials Letters & 41 & 1028 & 25 \\
\hline Construction And Building Materials & 131 & 2132 & 16 & Journal Of Materials Science & 40 & 751 & 19 \\
\hline International Journal Of Thermal Sciences & 110 & 3346 & 30 & Materials Chemistry And Physics & 38 & 1247 & 33 \\
\hline International Journal of Refrigeration & 107 & 2779 & 26 & Nanomaterials & 31 & 159 & 5 \\
\hline Journal Of Solar Energy Engineering & 101 & 2571 & 25 & Advanced Materials & 25 & 1334 & 53 \\
\hline Journal Of Applied Polymer Science & 97 & 2222 & 23 & Fibers And Polymers & 25 & 323 & 13 \\
\hline
\end{tabular}

\subsection{Specific Trends and Gaps}

The holistic context presented in Section 3.1 is complemented here with a more detailed discussion of the specific trends and research gaps that TESMs encounter, per TESM category.

\subsubsection{STESMs}

Water is the best liquid STESM for applications between ca. $4{ }^{\circ} \mathrm{C}$ and $100{ }^{\circ} \mathrm{C}$. Liquidform STESMs have a higher specific heat capacity and thermal conductivity compared with solid form STESMs such as rock [8]. For cooling applications below $0{ }^{\circ} \mathrm{C}$, certain mineral oils as well as water-glycol mixtures are typically used. Mineral oil, molten salts, liquid metals and alloys are examples of liquid STESMs [9] for high temperature applications. With increasing interest in CSP, blends (binary, ternary, and quaternary) of carbonates, fluorides and nitrates are used as STESMs. The most common molten salt is known as solar salt that consists of $60 \% \mathrm{NaNO}_{3}-40 \% \mathrm{KNO}_{3}[33,34]$. Solar salt represents the most typical commercially available high temperature STESMs systems, used as both the TES medium and heat transfer fluid (HTF). The maximum operation temperature of this mixture is $585{ }^{\circ} \mathrm{C}$ to avoid decomposition and it must be kept above $220^{\circ} \mathrm{C}$ to stay in the molten state. This brings some limitations on the design of storage systems. Two-tank storage methods are used to solve this problem. The research on Binary, ternary and quaternary inorganic blends is also driven to overcome this limit. For instance, a new low-cost molten salt blend $\mathrm{NaCl}-\mathrm{KCl}-\mathrm{MgCl}_{2}$ was shown to be stable up to $700{ }^{\circ} \mathrm{C}$ [67]. These multicomponent blends are, however, still at lower TRLs of development. Sand, rock, concrete, cast iron, cast steel, 
$\mathrm{NaCl}$ and brick are reported as the most common solid sensible thermal energy storage materials. Rocks show good thermal performance up to 20 years. Concrete based materials are attractive options as STESM due to their low cost and high storage capacity. Concretes can be used in high temperature storage systems up to $400^{\circ} \mathrm{C}$.

Because TES and the reduction in its cost/ $\mathrm{kWh}$ are essential for the deployment of CSP, other alternatives besides different blends are now being considered. One such alternative is the use of nanofluids, because of the unrealistically high specific heat enhancements reported, albeit with the research at a very low TRL. Another alternative entails a different CSP plant concept that involves the use of particulate solids as the STESM medium and HTF that has advances in TRLs at 4-5 for some components, such as the receiver or the heat exchanger. There is a particular demand for increasing the operating temperature of existing STESMs or finding new ones for higher temperature applications. The author of [68] designed economical concrete mixtures by using fly ash and polypropylene fiber mixtures as fillers to increase the operating temperature to $600{ }^{\circ} \mathrm{C}$.

Waste/inertized materials can be used to design alternative STESMs at a low cost. Inertized products such as by-products derived from mining and the metallurgical industry [69], asbestos-containing wastes [70], fly ashes from municipal solid waste [70], post-industrial ceramic [71], recycled nylon fiber from the textile industry [72], and demolition wastes [10], can be used as STESMs for high temperature thermal storage. Table 3 compares energy densities and costs of STESMs for high temperature applications. As can be seen, waste or by-products from industrial processes have the lowest cost with comparable energy densities to existing alternative STESMs.

Table 3. Properties of STESMs for high temperature applications.

\begin{tabular}{|c|c|c|c|c|c|}
\hline Category & STESM & $\begin{array}{l}\text { Operational } \\
\text { Temperature }\left({ }^{\circ} \mathrm{C}\right)\end{array}$ & $\begin{array}{l}\text { Energy Density } \\
\left(\mathrm{kJ} \mathrm{m}^{-3} \mathrm{~K}^{-1)}\right.\end{array}$ & Cost (Euro/kg) & Sources \\
\hline \multirow{4}{*}{$\begin{array}{l}\text { Waste/By- } \\
\text { products }\end{array}$} & Demolition Waste & $<750$ & $3500-4000$ & $<0.001$ & [10] \\
\hline & $\begin{array}{l}\text { Induction furnace slag (IFS) from } \\
\text { steel making process }\end{array}$ & $<1000$ & 1200-1850 & $<0.001$ & [73] \\
\hline & $\begin{array}{l}\text { Asbestos containing waste } \\
\text { (Cofalit) }\end{array}$ & $<1100$ & $2490-3220$ & $<0.001$ & [71] \\
\hline & Electric arc furnace slags (EAF) & $<1100$ & $3200-3400$ & $<0.001$ & [74] \\
\hline \multirow{5}{*}{ Solid } & Concrete & $<400$ & 1900 & 0.05 & [75] \\
\hline & Cast steel & $<700$ & 4700 & 4 & [75] \\
\hline & Magnesia Fire Brick & $<1200$ & 3500 & 2 & [75] \\
\hline & $\mathrm{NaCl}$ (Solid) & $<500$ & 1800 & 0.12 & [75] \\
\hline & Metal Alloys & $450-620$ & $3000-4500$ & NA & [76] \\
\hline \multirow{4}{*}{ Liquid } & Solar Salt $\left(\mathrm{NaNO}_{3} \mathrm{KNO}_{3}(50-50)\right.$ & $<600$ & 2800 & 0.4 & [76] \\
\hline & $\begin{array}{l}\mathrm{HITEC}, \mathrm{NaNO}_{3}-\mathrm{KNO}_{3}-\mathrm{NaNO}_{2} \\
(7-53-40)\end{array}$ & $<535$ & 2560 & 0.5 & [77] \\
\hline & Carbonate Salt & $<850$ & 3800 & 2.2 & [75] \\
\hline & Nitrate Salt & $<565$ & 3000 & 0.4 & [76] \\
\hline
\end{tabular}

The typical advantages and disadvantages of these various STESM categories are summarized in Table 4. 
Table 4. Advantages and disadvantages of various STESM categories (here the temperature ranges provided are just indicative but not exclusive. Subzero, medium and high temperatures represent below $0{ }^{\circ} \mathrm{C}$, between $\sim 4-100{ }^{\circ} \mathrm{C}$, and above $\sim 100{ }^{\circ} \mathrm{C}$, respectively).

\begin{tabular}{|c|c|c|c|c|}
\hline STESM Category & & Typical Temperatures & Advantages & Disadvantages and Challenges \\
\hline Pure solids & Ice & Subzero & $\begin{array}{l}\text { Cheap, abundant, simple, and } \\
\text { high TRL, non-toxic, higher heat } \\
\text { capacity }\end{array}$ & \\
\hline \multirow[t]{2}{*}{ Pure liquids } & Water & Medium & $\begin{array}{l}\text { Cheap, abundant, non-toxic, } \\
\text { higher heat capacity, high TRL }\end{array}$ & $\begin{array}{l}\text { For narrow temperature } \\
\text { applications, volumetric heat } \\
\text { storage density is low }\end{array}$ \\
\hline & Molten salt & High & $\begin{array}{l}\text { Commercially available, suitable } \\
\text { for high temperature } \\
\text { applications up to } 600{ }^{\circ} \mathrm{C}\end{array}$ & $\begin{array}{l}\text { Corrosion, high cost, higher } \\
\text { environmental impacts } \\
\text { comparing with natural solids }\end{array}$ \\
\hline \multirow{3}{*}{$\begin{array}{l}\text { Blend/composite } \\
\text { solids }\end{array}$} & Ceramics & High & $\begin{array}{l}\text { Thermally stable up to } 1200{ }^{\circ} \mathrm{C} \text {, } \\
\text { suitable for high temperature } \\
\text { applications, cheap }\end{array}$ & $\begin{array}{l}\text { Relative inhomogeneity between } \\
\text { different types if come as } \\
\text { waste/by-products, brittle }\end{array}$ \\
\hline & Rocks & Medium and high & $\begin{array}{l}\text { Good thermal and mechanical } \\
\text { stability, suitable for high } \\
\text { temperature applications up to } \\
1000^{\circ} \mathrm{C} \text {, high density, cheap, no } \\
\text { corrosive effect }\end{array}$ & $\begin{array}{l}\text { Low heat capacity, depletion of } \\
\text { natural sources, low thermal } \\
\text { conductivity }\end{array}$ \\
\hline & Wates & High & $\begin{array}{l}\text { Can be derived from } \\
\text { waste/inertized materials (such } \\
\text { as slags, asbestos and demolition } \\
\text { wastes), stable up to } 1000{ }^{\circ} \mathrm{C} \\
\text { (based on its origin), high heat } \\
\text { capacity, }\end{array}$ & $\begin{array}{l}\text { Need additional processes to } \\
\text { obtain uniform STESM }\end{array}$ \\
\hline Liquid blends & $\begin{array}{l}\text { Oils (e.g., } \\
\text { silicon oil) }\end{array}$ & Medium and high & $\begin{array}{l}\text { Suitable for medium } \\
\text { temperature applications up to } \\
400^{\circ} \mathrm{C} \text {, low freezing point }\end{array}$ & $\begin{array}{l}\text { High cost, do not freeze in the } \\
\text { system during the cold weather } \\
\text { or nights }\end{array}$ \\
\hline
\end{tabular}

\subsubsection{PCMs}

As was discussed (Section 2.2), one hyped class of PCMs are salt hydrates. Salt hydrates are popular because they are relatively cheap and abundant and have high volumetric energy storage densities. For example, the salt hydrate calcium chloride hexahydrate $\left(\mathrm{CaCl}_{2} 6 \mathrm{H}_{2} \mathrm{O}\right)$ with a melting temperature of about $29^{\circ} \mathrm{C}$ has a mass-related enthalpy of fusion of about $191 \mathrm{~J} / \mathrm{g}$ [50]. Due to the density in the liquid state of about $1.56 \mathrm{~kg} / \mathrm{L}$, the energy density related to the volume is about $298 \mathrm{~kJ} / \mathrm{L}$ [50]. This value is almost as high as the enthalpy of fusion of water/ice (approx. $330 \mathrm{~kJ} / \mathrm{L}$ ). In many cases, technical grade salt hydrates can be provided at a low cost of less than 1 EUR $/ \mathrm{kg}$ [78].

Despite their popularity, finding robust PCMs from salt hydrates appears a challenge. A major issue is that during the selection process, phase equilibrium knowledge is significantly overlooked or poorly understood, often resulting in supercooling and phase separation, thus negatively impacting their reversibility and cycling stability. The rule of thumb is to avoid incongruently melting compositions (including strictly incongruently melting peritectics, c.f. Section 1.3) and instead resolve to congruently melting compositions (which are also many among salt hydrates, e.g., Figure 3 and [78]) or non-supercooling eutectics. Semi-congruently melting salt hydrates may also be used in applications by taking certain measures on a material or storage level. In this case, their phase transition must be well-understood prior to moving into TES applications, to avoid/properly control the undesirable phase separation, supercooling, and related challenges. In applications, the corrosivity of salt hydrates must also be taken into account, for which metallic heat exchangers with special coatings or heat exchangers fabricated of plastic along with careful materials compatibility testing can be helpful. So far, salt hydrates and LHTES systems based on salt 
hydrates have only been commercialized in a few cases (among others by the companies Rubitherm [79] (based on SAT, [80]), Sunamp [81], PLUSS [82], and Swerod [83]). This is likely owing to poor phase equilibrium understanding, poor understanding of mechanisms enabling successful thickening using additives, and additional complex phase change behaviors which require both careful PCM development and a storage design that takes these inherent characteristics into account. These challenges in salt hydrates have pushed researchers to seek alternative materials for LHTES applications.

The organic PCM sub category alkanes, commonly referred to as paraffins, can be considered the next most-investigated PCM category after salt hydrates ([12,45,84]). These gained popularity for their simple phase change at a variety of temperatures with moderate phase change enthalpies and for many alkanes being relatively safe (non-toxic) as a material to use. However, alkanes tend to pose some challenges such as solid-solid phase transitions, only moderate phase change enthalpies and high flammability $([12,84])$. Alkanes are also among commercial PCMs from, e.g., Rubitherm [79]. One particular disadvantage of both salt hydrates and alkanes is their non-renewable nature, as they are extracted from depletable sources. This is one of the reasons behind the recent advance of sustainable PCMs in the latent heat storage field. Several material categories belong to this group, and some of the most prominent ones in the PCM-context are represented by fatty acids, esters, and sugar alcohols.

Fatty acids are naturally found in oils and algae and are non-toxic [85]. Depending on the absence or presence of double or triple bonds, they are defined as either saturated or unsaturated, respectively. Generally, saturated ones have been studied more intensely than their unsaturated counterparts. For PCM applications, mostly fatty acids with carbon numbers (n) ranging from 3 to 9 have been investigated with melting points from $16-74{ }^{\circ} \mathrm{C}$ and enthalpies of fusion from 150 to $220 \mathrm{~J} / \mathrm{g}$ [86]. Saturated fatty acids normally present low degrees of supercooling, although this is suspected to strongly depend on the thermal history [87]. They are mildly corrosive and have been reported to be thermally stable upon cycling.

Esters are organic substances formed by the union of a carboxylic acid with an alcohol, and can be encountered in natural renewable sources such as vegetable and animal fats [88]. As they are the result of the combination of acids and alcohols, millions of possible esters with specific thermophysical properties exist. Esters present a wide range of melting temperatures and enthalpies approximately of $-25-100{ }^{\circ} \mathrm{C}$ and $100-50 \mathrm{~J} / \mathrm{g}([11,89-93])$ and are characterized by little to no supercooling, high chemical and thermal stability and no corrosiveness and are only moderately flammable [94]. Still, many are not commercially available, and they remain mostly unexplored $[95,96]$. This is certainly one of the main barriers for their investigation.

Polyols (poly-alcohols, many referred to as sugar alcohols) have undergone substantial research as PCMs in the past two decades. These have low to moderately high phase change temperatures (ca. $-15-250^{\circ} \mathrm{C}$ ) and considerable enthalpies, with (ca. 100-400 kJ/kg). These are attractive as PCMs for their renewable origin, plus certain polyols such as erythritol, xylitol, and sorbitol, are non-toxic (food-grade) [19,97]. However, the commercialization of polyols into TES applications is hindered by material challenges such as substantial supercooling, hysteresis, glass transition, succumbing to metastable states at varying heating/cooling rates, thermally activated change (with possible degradation) in ambient conditions, plus higher costs particularly for a large-scale [19]. Polyols become crystalline when water is present, undergoing plasticization, and tend to become amorphous in the absence of water, succumbing to glass transition [97]. Thus, water may be investigated as a plasticizer to ensure crystallization in polyols, however, this can compromise the storage density and pose practical challenges in maintaining this water intact in the polyol particularly if the TES application is at or above $100{ }^{\circ} \mathrm{C}$.

While bio-based PCMs are in general considerably more expensive than salt hydrates, they are extractable from renewable feedstock which makes them particularly attractive. Bio-based PCMs have a lower TRL than salt hydrates, and they are being commercialized by some companies such as Croda [98]. Being bio-based, there is great potential in these 
materials as PCMs to reach lower costs in the future by, e.g., using more cost-effective raw materials and synthesis steps, and also creating larger markets for these niche products. Erythritol (a polyol) is one such example, produced today using maize but can also be produced using, e.g., wheat straw or crude glycerol (coming as a by-product during biodiesel, bioethanol or soap production) for a lower cost of production [99]. Table 5.

The typical advantages and disadvantages of these various PCMs are summarized in

Table 5. Advantages and disadvantages of various PCM categories (here the temperature ranges provided are just indicative but not exclusive. Subzero, low, medium, relatively high, and high temperatures represent below $0{ }^{\circ} \mathrm{C}, 0-30{ }^{\circ} \mathrm{C}, \sim 4-100{ }^{\circ} \mathrm{C}$, $\sim 100-300{ }^{\circ} \mathrm{C}$ and above $\sim 300{ }^{\circ} \mathrm{C}$, respectively).

\begin{tabular}{lll}
\hline PCM Category & Typical Temperatures & Advantages \\
\hline \multirow{2}{*}{ Ice (or snow) } & $\sim 0{ }^{\circ} \mathrm{C}$ & $\begin{array}{l}\text { Cheap, abundant, simple and } \\
\text { high TRL, non-toxic, higher } \\
\text { volumetric heat storage density }\end{array}$ \\
& & olume
\end{tabular}

\begin{tabular}{|c|c|c|c|c|}
\hline & Salt hydrates & Low to relatively high & $\begin{array}{l}\text { Cheap, abundant, some } \\
\text { non-toxic, quite high } \\
\text { volumetric heat storage density } \\
\text { and thermal conductivity }\end{array}$ & $\begin{array}{l}\text { Non-renewable, poor cycling } \\
\text { stability if chosen from } \\
\text { incongruent compositions, high } \\
\text { degree of supercooling, corrosive } \\
\text { to metals, some can be toxic }\end{array}$ \\
\hline \multirow[t]{4}{*}{ Inorganics } & $\begin{array}{l}\text { Metals and } \\
\text { their alloys }\end{array}$ & Relatively high to high & $\begin{array}{l}\text { High volumetric heat storage } \\
\text { density and very high thermal } \\
\text { conductivity }\end{array}$ & $\begin{array}{l}\text { Expensive, competition against } \\
\text { other metal applications, } \\
\text { non-renewable }\end{array}$ \\
\hline & Salt blends & Relatively high to high & $\begin{array}{l}\text { Abundant, some non-toxic, } \\
\text { quite high volumetric heat } \\
\text { storage density and thermal } \\
\text { conductivity }\end{array}$ & $\begin{array}{l}\text { Non-renewable, poor cycling } \\
\text { stability if chosen from } \\
\text { incongruent compositions, } \\
\text { corrosive to metals, some can be } \\
\text { toxic }\end{array}$ \\
\hline & Alkanes & Subzero and medium & $\begin{array}{l}\text { Some non-toxic, relatively high } \\
\text { TRL and lower cost }\end{array}$ & $\begin{array}{l}\text { Lower volumetric heat storage } \\
\text { density and thermal conductivity, } \\
\text { some can be toxic, flammability, } \\
\text { non-renewable, corrosion of } \\
\text { plastics }\end{array}$ \\
\hline & Fatty acids & $\begin{array}{l}\text { Medium and relatively } \\
\text { high }\end{array}$ & $\begin{array}{l}\text { Bio-based, from renewable } \\
\text { sources, broad range of melting } \\
\text { temperatures }\end{array}$ & $\begin{array}{l}\text { Corrosive, less chemically inert, } \\
\text { lower volumetric enthalpies } \\
\text { compared with salt hydrates, } \\
\text { sometimes polymorphism }\end{array}$ \\
\hline \multirow[t]{2}{*}{ Organics } & Polyols & $\begin{array}{l}\text { Medium and relatively } \\
\text { high }\end{array}$ & $\begin{array}{l}\text { Moderate to high volumetric } \\
\text { heat storage densities, } \\
\text { bio-based and renewable, } \\
\text { non-corrosive, broad range of } \\
\text { phase change temperatures, } \\
\text { often non-toxic (many even } \\
\text { food-grade) }\end{array}$ & $\begin{array}{l}\text { Can be prone to glass transition, } \\
\text { polymorphism, metastability, } \\
\text { thermally activated change, high } \\
\text { degree of supercooling, high costs } \\
\text { at high purity (due to niche } \\
\text { markets for large-scale } \\
\text { production) }\end{array}$ \\
\hline & Esters & $\begin{array}{l}\text { Medium and relatively } \\
\text { high }\end{array}$ & $\begin{array}{l}\text { Non corrosive, chemically } \\
\text { stable, bio-based, from } \\
\text { renewable sources, broad range } \\
\text { of melting temperatures }\end{array}$ & $\begin{array}{l}\text { Lack of commercially available } \\
\text { pure materials (due to lack of } \\
\text { applications), lack of data, lower } \\
\text { volumetric enthalpies compared } \\
\text { with salt hydrates, some } \\
\text { polymorphism }\end{array}$ \\
\hline Clathrates & & Low & Rather abundant & $\begin{array}{l}\text { Non-renewable, corrosive to } \\
\text { metals, lower TRL }\end{array}$ \\
\hline
\end{tabular}

\subsubsection{TCMs}

TCMs rely on the reversible sorption processes involving adsorption, chemical reactions or absorption (c.f. Section 2.3). The most versatile class of sorbents are the two- 
component sorbents or composites [100], composed of a porous solid as an active matrix (e.g., silica gels, zeolites, mesoporous silicates [101], vermiculite and MOF [102]) or an inactive matrix (e.g., silicon foam [103], expanded graphite, or porous metals) filled with hygroscopic salt hydrates (e.g., $\mathrm{LiCl}, \mathrm{CaCl}_{2}, \mathrm{MgSO}_{4}, \mathrm{SrBr}_{2}$ ). These are synthesized to enhance water sorption capacity as well as heat and mass transfer on one hand, and on the other hand to avoid deliquescence, swelling and agglomeration of the salt hydrates during sorption/desorption cycles. These sorbents have the advantage of tailoring sorption capacity by changing the content of salt and porous structure. Further advantages are low desorption temperature, low price and a simple production method. The current trend is focused on increasing the amount of the salts in the matrices to achieve higher sorption capacity, while the used matrices are mainly commercial ones and less effort is dedicated to tailoring the structure of matrices [101,104].

The design of efficient water adsorbents with advanced properties is motivated by an increase in the water sorption capacity and regeneration of the sorbent at a low temperature (up to $120^{\circ} \mathrm{C}$ ). Zeolites, as traditionally highly hydrophilic adsorbents, are microporous sodium aluminosilicates with 3D structures containing channels with pore openings from 0.3 to $1.2 \mathrm{~nm}$. Although there are more than 200 different structure types of zeolites, only high-alumina zeolites are considered suitable for sorption heat storage, such as Zeolite A, Zeolite $X$ and Zeolite $Y$. These are manufactured synthetically. Ion exchange modification of zeolites with magnesium and lithium cations increases water sorption capacity, however, it also increases the charging temperature, which is a drawback. To overcome this, granulated binder-free zeolites (A, X and Y) were successfully manufactured. Thereby, an increased water sorption capacity, e.g., 16\% for Zeolite X [105], was realized while maintaining the charging temperature, which is still rather high for solar energy storage (up to $250{ }^{\circ} \mathrm{C}$ ). The crystallinity of Zeolite X can degrade under hydrothermal stress in the aqueous atmosphere of an adsorption storage device [106], another challenge requiring further R\&D. Within recent developments, dealumination of granulated binder-free Zeolite $\mathrm{Y}$ led to lower charging temperatures, e.g., at $30{ }^{\circ} \mathrm{C}$ and to higher water sorption capacity due to the introduction of mesopores into microporous structure forming hierarchical zeolite [107].

In the last decade, new adsorbents with energy storage densities up to $530 \mathrm{kWh} / \mathrm{m}^{3}$ have been successfully proposed. Namely, microporous aluminophosphates, FAPO-34, APO-18, APO-Tric, and APO-LTA $([26,27,108])$ revealed their advantages over zeolites concerning a low charging temperature due to a hydrophobic-hydrophilic character, high water capacity and high adsorption enthalpy. APO-Tric exhibited better hydrothermal cycling stability than SAPO-34, the commercial water aluminophosphate adsorbent [27]. Concerning the cycling stability, the crystalline structure of SAPO-34 was found to become amorphous after 50 cycles while the APO-Tric structure remained crystalline 50 cycles under the working conditions: adsorption at $40{ }^{\circ} \mathrm{C}$ and desorption at $150{ }^{\circ} \mathrm{C}$ at 56 mbar water vapor pressure [109]. Overall, it has been shown that these adsorbents with adsorption equilibrium with adsorbate (water), characterized by S-shaped adsorption isotherms, are advantageous for the heat pumps and chillers. Metal-organic frameworks (MOFs) $([26,110])$ are another innovative class of adsorbents, which possess very large water sorption capacity and heat storage capacity, S-shaped adsorption isotherms and require low charging temperature. The main disadvantage, however, is their high price. As recent research results indicate, ettringite, is a low cost mineral (a component in some cements) which possesses high energy density $\left(\sim 500 \mathrm{kWh} / \mathrm{m}^{3}\right)$, low corrosiveness, non-toxicity and low working temperature $\left(\sim 60^{\circ} \mathrm{C}\right)$ with promise as a TCM [111].

Concerning the costs of these TCMs, zeolites as low-cost adsorbents are already on the market (e.g., CWK, Clariant, Silkem, Zeolyst and Grace). Some aluminophosphates and MOFs are also manufactured, yet they are much more expensive than zeolites. Composites composed of salt hydrates and porous matrices are less expensive than aluminophosphates, especially if a natural matrix is used, such as vermiculite clay. Ettringite's cost is as low as $700 \mathrm{USD} / \mathrm{m}^{3}$ in comparison with $4300 \mathrm{EUR} / \mathrm{m}^{3}$ for silica gel, 2000-3000 EUR/ $\mathrm{m}^{3}$ for Zeolite $13 \mathrm{X}$ or more than $42,000 \mathrm{EUR} / \mathrm{m}^{3}$ for hydrates of $\mathrm{SrBr}_{2}$ [111]. With salt-water chemical 
reaction systems being at a relatively low cost ranges, some of these (e.g., $\mathrm{CaO} / \mathrm{Ca}(\mathrm{OH})_{2}$ reaction) are already on the market via companies such as SaltX AB [112].

The water-based TCS systems can be designed as open or closed-systems as water is safe to be released to the environment. Whereas, the TCS systems using non-water sorbates (e.g., $\mathrm{NH}_{3}, \mathrm{CO}_{2}$, ethanol and methanol) which have toxic or flammable properties must be designed as closed systems. Hence, the water-based TCS systems maintain a larger popularity today, for the considerable ease of system design. Nevertheless, for the very compact energy storage densities offered by these other non-water-based TCS systems, these systems are gaining significant interest. Therefore, TCS system design with, e.g., $\mathrm{NH}_{3}$ and $\mathrm{CO}_{2}$ has the competitive advantage of benefitting from mature learning curves of refrigeration systems using these as refrigerants (R-717 and R-744), and sharing similar operating configurations and components.

The diversity of these reaction types gives rise to rather different operational temperature ranges for applications, which on one hand shows the versatility of the concept, but on the other hand makes every individual reaction a special case. The biggest concern, therefore, is that the envisaged application defines the boundary conditions with respect to the temperature range, reaction kinetics and storage capacity as well as the spatial and/or temporal decoupling of supply and demand of thermal energy. In an ideal world, the once set boundary conditions of an application allows for the selection of the appropriate TCM from a variety of established reaction types and materials. However, the real world is lacking this variety of ready-to-install TCS systems due to a manifold of reasons. These reasons can be encountered on the quantum-chemical, molecular, particle, reactor and system scale. In each scale, different theoretical tools allow for a system modelling to derive parameters for upscaling processes and tuning of the properties, as summarized in Figure 12.

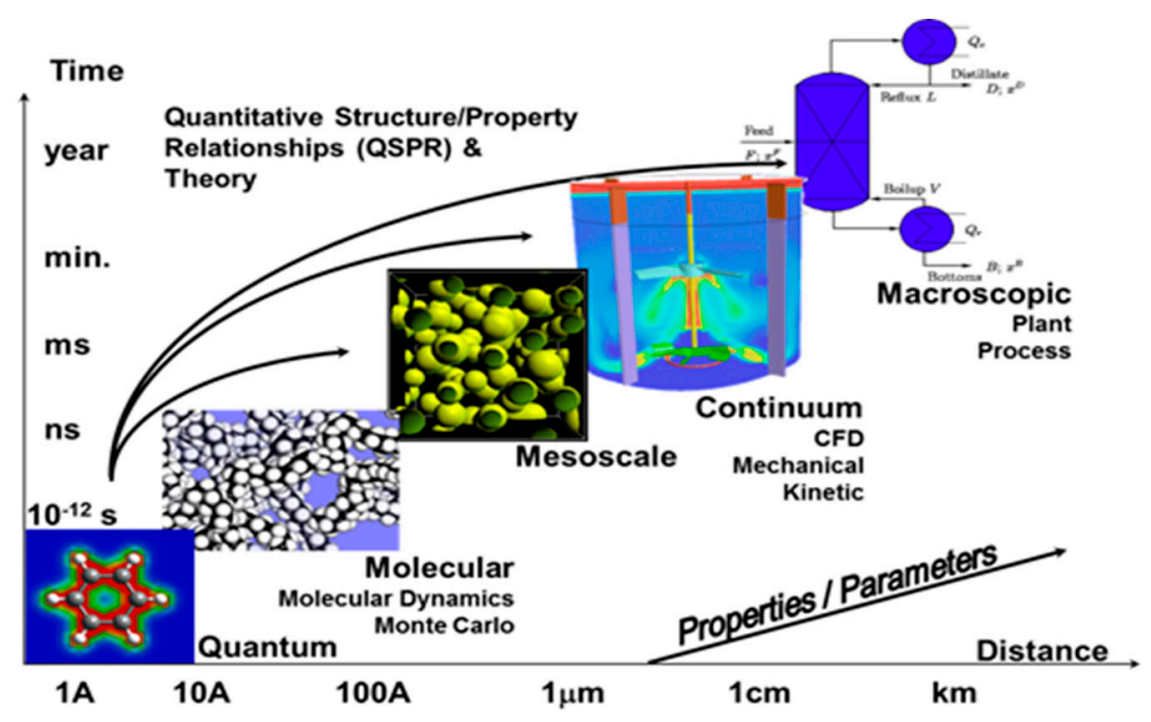

Figure 12. Different scales of quantitative structure-property relationships and theoretical tools applied [113].

The first medium-sized prototype reactors were developed to elucidate a system performance on the kilogram scale in lab environments [114], and salt hydration-based reactors as prototype. However, most TCMs reside at low TRLs. The advantage of the solid-gas reactions being the basis of TCMs, is the tunability of the reaction conditions with respect to temperature and pressure (of the reactive gas) allowing for optimization of the overall performance. Nevertheless, the major drawback so far is the uniqueness of most systems under investigation and, therefore, the restricted transferability of insights gained into the reaction parameters of a specific TCM within the same compound class or even beyond. 
At a more specific level, e.g., to overcome the shortcomings of a poorer storage capacity than expected in TCS, the use of technical gases (i.e., in-place of the pure gas) such as carbon dioxide or ammonia is a solution, because these gases are easy to handle in an industrial scale, inexpensive, and if kept in closed cycles as safe as water vapor. There is fundamental research investigating the performance of moisturized carbon dioxide in oxide-carbonate cycles $[25,115]$ as well as the use of ammonia with transition metal salts [14]. Especially in the case of copper sulfate, the heat release is extremely rapid and intense that only the use of an inert carrier material allows for a reversible application [52]. Table 6.

The typical advantages and disadvantages of these various TCMs are summarized in

Table 6. Advantages and disadvantages of various TCM categories (here the temperature ranges provided are just indicative but not exclusive. Low, medium, and high temperatures represent below $100{ }^{\circ} \mathrm{C}, \sim 100-450{ }^{\circ} \mathrm{C}$ and above $\sim 450{ }^{\circ} \mathrm{C}$, respectively).

\begin{tabular}{|c|c|c|c|c|}
\hline \multicolumn{2}{|c|}{ TCM Mechanism/Material } & \multirow{2}{*}{$\begin{array}{l}\text { Typical Temperatures } \\
\text { Medium }\end{array}$} & \multirow{2}{*}{$\begin{array}{l}\text { Advantages } \\
\text { Good energy storage density, cost, } \\
\text { good hydrothermal cycle stability }\end{array}$} & \multirow{2}{*}{$\begin{array}{l}\text { Disadvantages and Challenges } \\
\text { High desorption temperature, low } \\
\text { thermal conductivity }\end{array}$} \\
\hline \multirow{4}{*}{ Adsorption } & Zeolites & & & \\
\hline & Silica gels & Low up to $90{ }^{\circ} \mathrm{C}$ & Low desorption temperature, cost & $\begin{array}{l}\text { Low energy storage density, low } \\
\text { thermal conductivity }\end{array}$ \\
\hline & Aluminophosphates & Low, $60-90{ }^{\circ} \mathrm{C}$ & $\begin{array}{l}\text { High energy storage density, low } \\
\text { desorption temperature, excellent } \\
\text { hydrothermal cycle stability }\end{array}$ & Low thermal conductivity, cost \\
\hline & $\begin{array}{l}\text { Metal organic } \\
\text { frameworks (MOFs) }\end{array}$ & Low up to $90^{\circ} \mathrm{C}$ & $\begin{array}{l}\text { High energy storage density, low } \\
\text { desorption temperature, } \\
\text { hydrothermal cycle stability }\end{array}$ & Low thermal conductivity, cost \\
\hline \multirow{5}{*}{ Chemical reactions } & Salt hydrates & Low to medium & $\begin{array}{l}\text { Moderate energy storage density, } \\
\text { medium costs, reasonable cycle } \\
\text { stability }\end{array}$ & $\begin{array}{l}\text { Low thermal conductivity, } \\
\text { corrosion }\end{array}$ \\
\hline & Halide ammines & Medium & $\begin{array}{l}\text { High energy storage density, good } \\
\text { cycle stability }\end{array}$ & $\begin{array}{l}\text { Costs, reversible mass transport } \\
\text { only if on matrix support }\end{array}$ \\
\hline & Metal carbonates & Medium to high & $\begin{array}{l}\text { Low costs, tunability via } \mathrm{CO} 2 \\
\text { pressure }\end{array}$ & $\begin{array}{l}\text { Poor cycle stability, humidity } \\
\text { required }\end{array}$ \\
\hline & Redox reactions & High & $\begin{array}{l}\text { High temperature application, } \\
\text { tunability via aerobic/anaerobic } \\
\text { conditions }\end{array}$ & High costs \\
\hline & Metal hydrides & High & High energy storage density & Corrosion (of metals) \\
\hline Absorption & Liquid salt solutions & Low & $\begin{array}{l}\text { High TRL, relatively inexpensive } \\
\text { chiller solutions }\end{array}$ & Restricted to cooling applications \\
\hline $\begin{array}{l}\text { Adsorption }+ \\
\text { Chemical reaction } \\
+ \text { Absorption }\end{array}$ & $\begin{array}{l}\text { Composites of } \\
\text { porous matrix and } \\
\text { salts/oxides }\end{array}$ & Low to Medium & $\begin{array}{l}\text { High energy storage density, cost, } \\
\text { good cycling stability }\end{array}$ & $\begin{array}{l}\text { Low thermal conductivity, } \\
\text { corrosion }\end{array}$ \\
\hline
\end{tabular}

\subsubsection{Common TESM Trends}

In the pursuit of ever more enhanced materials, additives such as nanoparticles have been increasingly used in the making of TESM blends [116]. Micro-scale molecular chemical calculations and nanocomposite numerical behavioral characterization [117-119] have shown a recent increase in interest among the research communities [120,121].

Adequate material property understanding is crucial for engineers in designing TESs for actual application use. Excellent characterization methods have been developed by the research communities ([21,122-125]), contributing superbly to better scientific understanding of diverse characterization procedures, each suitable to a specific set of working conditions. However, this also leads to overly complicated comprehension for engineering to discern the most suitable testing means and testing results for an actual physical project. Efforts have thus been put into categorization and mapping of TES per application with specific designs for each of the engineering fields, e.g., from solar cooker with storage [126,127] to air condition with storage [128] to storage integrated building envelopes [129]. 


\subsubsection{Barriers and Missing Links from the Laboratory to Application}

When looking at the battery (i.e., for electrochemical storage) as a product, it is made up of many materials and the product itself is a package of these materials. Likewise, if a TESM is considered as a product alone, it is very difficult to adapt it to different needs of the applications. Moreover, many products that are used in everyday life today will not work without a battery. This is what makes batteries inevitable. Currently, most energy systems continue to operate without the use of a TESM product. However, the urgent need of transition to carbon neutral systems makes TESMs also inevitable. The main barrier for the implementation of TES in an energy system is that there is not a unique recipe to be adopted, TES systems are not "plug and play" but need to be researched and designed ad hoc, meaning that a design based on the TESM is inevitable too. The key challenges for TESM developers and the industry are to show how TESMs are inevitable and how to present them in a thermal battery package ready for plug and play. Despite all technological marvels, people's perception ultimately plays a deterministic role in deciding what is trendy and thus what solutions are finally implemented on a large scale. For instance, the house is no longer a status symbol, while an electric vehicle is (particularly in developed countries). Thus, TESMs packaged in a plug and play thermal battery requires awareness building and dissemination to reach every corner of society to establish its rightful status symbol as a true enabler of carbon neutral energy systems.

The main barrier for STESMs for applications with limited available space is compactness. In urban areas for building applications, finding a space even for a domestic hot water (DHW) tank may not be possible. For industrial applications, finding the material with the matching temperature requirements in the large quantities needed with robustness and at competitive prices can be a barrier. STESMs can deplete natural materials such as rocks, as STESM is not a sustainable way of solving energy problems, and requires competitive renewable alternatives. Materials for industrial applications above $750{ }^{\circ} \mathrm{C}$ are needed for especially new generation CSP plants. Although some STESMs such as molten salts and metal alloys are attractive choices here, their corrosion issues necessitate taking extra measures. Whereas, materials used to prevent corrosion may be expensive and also increase operation cost. CSP is an application where the opportunity cost for a robust TESM is higher and therefore R\&D to address these STESM challenges is a worthy cause.

To this day, inorganic and organic PCM alike presents several unsolved challenges mainly connected with their kinetic behavior, posing a certain unpredictability. On the one hand, salt hydrates are typically characterized by slow nucleation, which translates to high degrees of supercooling. This is detrimental to typical LHTES applications as it broadens the operational temperature range needed to melt and crystallize the PCM, thus lowering its advantage in comparison with seasonal storage [7]. On the other hand, while organic PCMs usually show low degrees of supercooling, they often show the tendency to crystallize in different arrangements (i.e., solid phases) despite maintaining the same chemistry and overall composition. This phenomenon is referred to as "polymorphism", and different crystalline structures are then called "polymorphs" or "polymorphic forms". Polymorphism represents an obstacle to the use of organic PCMs in LHTES, since different polymorphs present very different thermophysical properties such as melting points, enthalpies, thermodynamic stability, and solubility [11].

Supercooling and polymorphism are both of a kinetic nature, although they are disconnected from each other. In the case of supercooling, the PCM nucleates slowly due to a high energy barrier, whereas polymorphism in organic compounds is generally caused by the rotational degrees of freedom and the ability of the molecules to arrange themselves in different patterns. Currently, supercooling and polymorphism are managed through trial-and-error methodologies such as the addition of nucleating agents [130] or Peltier elements [7] for the former, and the usage of specific solvents and conditions for the latter [131]. Nevertheless, both phenomena are still far from being completely understood and still represent a challenge to the further development and integration of PCMs in energy-storing setups [132,133]. 
The standardization of TESMs characterizations within common TES platforms to obtain a common consensus is an essential step for accelerating their TRL progression. Although, e.g., IEA TCP activities have significant contributions here (see Section 2.2), there is also still a lot to accomplish. Long-term stability of PCMs is one such key parameter with not enough attention and standardization yet. In IEA SHC/ECES Task 58/Annex 33 [22], to test the long-term stability of PCMs, these were subjected to melting and solidification processes representing the conditions of the intended application. Therein, the characterization of 18 experimental devices to investigate the long-term stability of PCM were presented [134]. These experiments were divided into thermal cycling stability tests, tests on PCM with stable supercooling, and tests on the stability of phase change slurries (PCSs). In addition to these experiments, appropriate methods to investigate a possible degradation of the PCM were introduced. Considering the diversity of the investigated devices and the wide range of experimental parameters, this article concludes with recommendations on further work toward a standardization of PCM stability testing [134]. This is a valuable standardization step in the application-specific characterization of PCMs, while it is also an indication that there is an enormous amount of work ahead to achieve standardization in a true sense for all TESMs. Xu, 2021 [135] highlighted the benefits and also the lack in the TES R\&D, of TESM characterizations at the material, component, and system-scales to apprehend the complete spectrum of TESM behavior, prior to moving into full-scale TES applications. This becomes a matter of where the R\&D budget should be spent, i.e., to establish a sound basis or to patch-up and retrofit a poorly designed application.

Low thermal conductivity of a majority of PCMs and TCMs (as well as certain TESMs) has been an age-long battle, resulting in a poor heat transfer and therein the TES charging and discharging power. Organic PCMs suffer from poorer thermal conductivities than inorganic PCMs, which albeit have altogether poor heat transfer. TCM-adsorbents, particularly zeolites, aluminophosphates and composites based on silica matrices, encounter poor thermal conductivities. The state-of-art today for thermal conductivity improvement or TCMs comprise of coating of the TCM-adsorbents on metal plates/foams or preparing composites by impregnating the PCMs or TCM-absorbents in materials with high thermal conductivity, such as expanded graphite, aluminum and copper. This is also referred to as micro-encapsulation, concerning PCMs. PCMs are also macro-encapsulated in capsules (of, e.g., spherical and ellipsoidal geometries) fabricated of materials with better thermal conductivities and/or for maintaining the bulk volume in-tact in the TES component in both liquid and solid states [7,135]. Nanoparticle addition has also been a trend as a potential means for thermal conductivity improvement of, e.g., PCMs; however, this is received with mixed critique, as the high-thermal conductivity particles are only dispersed (not interconnected) in the bulk of the PCM, posing a higher thermal resistance.

The cost of PCMs and TCMs is also one barrier to reach commercialization. Salt hydrates come at lower prices. However, improper selection has most often led to a bad reputation which needs rectification by proper selection and comprehension. Alkanes (paraffins) and similar non-renewable PCMs as well as many other bio-based organic PCMs have rather high to very high costs, for the purity which comes at a cost, and because they are in the niche markets. Particularly the bio-based organic PCMs, however, have a great potential to reach lower costs with further R\&D on innovative low-cost production processes and for market expansion. Here, a hindrance to their large-scale exploration, however, is the lack of clear extraction routes from renewable feedstock. From adsorption-based TCMs only zeolites have commercially competitive prices, whereas, from chemical reactions-based TCMs, mainly salts (e.g., for hydration, hydroxide or hydride formation, ammoniation or carbonation), can be considered rather inexpensive. A dealbreaker concerning cost, however, is not merely the material cost but the component cost and the overall TES system, to enhance heat transfer and mass transfer for satisfactory thermal charging and discharging powers (particularly in active LHTES systems and TCS). The relative lack of techno-economic analyses and life cycle analyses (LCAs) of TES systems is a strong barrier for their commercialization. The benchmarking of these various 
system's techno-economic analyses is also currently amiss, which is essential for developing standards to enable accurate comparisons to find system-specific storage solutions.

Beyond the technical and economic barriers to the widespread exploitation of TESMs for numerous TES applications, there are also soft aspects that govern the way forward. These include political and legislative trends and incentives that favor energy storage for the most part in terms of electricity storage, where direct storage in, e.g., batteries, is dominating. Whilst innovative concepts such as power-to-heat and power-to-cold are emerging, these still require significant dissemination and awareness building towards all stakeholders in the energy chain and most importantly to the political and legislative decision makers. The usual norm of electrical battery storage must be apprehended handin-hand with all the other energy storage counterparts, such as mechanical energy storage (e.g., pumped-hydro, compressed-air and flywheels), electromagnetic storage (e.g., super capacitors) and in chemicals (e.g., hydrogen) [136] and last but not the least: TES.

With more than half of the global final energy used on thermal demands [1] the gravity of TES is unequivocal. Entities such as IEA and its TCPs on, e.g., SHC [137], ECES [138] DHC [139], as well as IRENA [140] and others already contribute significantly in promoting the role of TES (particularly beyond water and ice). However, the target audience of these channels will need to be further diversified while even more rigorous communication and dissemination actions will prove beneficial. A dilemma pertains also in the social acceptance of TES, as a relatively new technology (as opposed to, e.g., electricity and batteries). The Spanish case study on TES in buildings by [23] critically discusses social barriers to TES deployment with universal applicability to the global context as well. A key conclusion is that there is a lack of awareness and/or poor comprehension of what TES encompasses, a resistance to change from the comfort zones of conservative technologies, and a mistrust on the long-term success of the 'new' solutions in TES [23]. Concentrating research efforts to identify the socio-political drivers and barriers of TES and TESMs, also in other countries, regions (e.g., EU) and globally will be invaluable future steps.

\section{Concluding Remarks-What Do We Really Need to Do to Make TESM Fly?}

The concluding remarks here consider various drivers with the capacity to enable the three levels of decision-making concerning TES materials, namely: (1) thermo-physical and chemical properties (i.e., technical viability), (2) costs which come hand-in-hand with the technical viability, followed by (3) environmental and social aspects of inclusive political facets for sustainability.

In a carbon-neutral future, we can no longer rely on renewables being supported by fossil fuel-based systems. We, as TES designers, need to show that TESMs provide different approaches for an uninterrupted supply of renewables and the requirements that must be overcome. We need to address the wrong perception of "energy storage" that alienates thermal energy storage. The initial boom of TES and TESM R\&D in the 1970s haltered during the 1980s-1990s (e.g., Lane, 1983 [38], DLR and NASA [141]) possibly owing to the oil crisis and the accompanied financial downfall. TES is popular again because of the enormous demands for renewables, more efficient energy turnaround, and the need for compact storage, with the reality of climate change. We as TESM designers and TES developers need to make sure the boom does not stop again, and use this as a driver to maximally realize the potential of TES to decarbonize energy systems. We need to identify trends to profit from the lessons learnt from the past, so we do not make the same mistakes.

R\&D on STESMs requires a search for large-scale renewable alternatives, a systematic investigation of waste and/or industrial by-product alternatives to achieve relatively homogeneous thermophysical properties and to confront, e.g., corrosion issues of the choices today.

Proper understanding of the molecular dynamics of PCMs on the atomic-scale will allow better understanding of the crystallization, such as the glass transition, coring and supercooling aspects, as well as the dynamic and stability constraint in various amorphous 
phase change transitions $[142,143]$. Three points of numerical and analytical work required to further advance the development of TESMs are to:

1. Determine the theoretical limits of the PCMs' (and TCMs') thermo-physical properties;

2. Achieve molecular-level accurate prediction of crystallization and melting behavior;

3. Demonstrate through pilot projects, tailor-made energy storage materials that conform to the user requirements, show socio-economic soundness and contribute to technical advancement.

It has become clear up to now, that TCMs need to be designed and engineered first on the molecular level, by focusing on optimal inter-atomic interactions and mass-transport on a sub-micro-scale. Thus, the initial steps here should be the following:

1. Synthesis of new TCM adsorbents with appropriate chemical composition and pore sizes in accordance with cost-efficient and green principles (used reagents, solvents, etc.) and without hysteresis during sorption process;

2. Detailed microscopic, spectroscopic, and diffraction-based structure characterization. The exact knowledge about the structure is an enabling tool for a targeted synthesis of new materials and processes, i.e., structure-property relationship.

Then the next steps should be on the material level by maximizing the sorption performance, heat and mass/vapor transport, and hydrothermal stability at operation conditions, such as the following:

3. Evaluation of sorption mechanism, thermophysical properties and numerical modelling (i.e., interactions of materials with working fluids, the reaction dynamics) for further optimization of synthesis;

4. Improvement of the thermophysical properties to increase sorption performance.

Thereafter, the final steps should concentrate on the system (pilot) level, by focusing on the performance of the materials in a storage device.

The leading ways forward to make TES and therein TESMs fly on the market requires a more realistic design of TES systems based on innovative TESMs. This necessitates a universally approved common set of performance indicators, including and not limited to guaranteed technical performance, optimized control strategy, economic soundness and social acceptance [144]. It is also necessary to make greater use of the additional benefits of TESMs and to emphasize these benefits more in marketing, e.g., the possibility of passive temperature stabilization using PCMs or the possibility of air dehumidification using TCMs with water as a sorption partner. Attaining these indicators and added values covering the holistic system from TESM testing/characterization to component design and to system integration with economic, social and environmental outcome mapping will be essential in undertaking TES-based projects and in raising investors' interest in promoting and introducing the technology [145].

Figure 13 depicts the three spheres that drive TESM research and the synergies required between these spheres, to truly make TESMs fly on the market. This is indeed the ultimate goal we anticipate and wish for. That is where the TES application requirements and TESM characteristics are combined with socio-economic, environmental, and other (e.g., political) aspects to achieve a successfully commercialized TES design, i.e., in high a performing and sustainable TES with sustainable TESMs.

A circular economy perspective is essential when designing TESMs. That is, closing the circular economy loops between the sources of surplus materials and thermal energy (from, e.g., industries, power plants, and commercial sectors such as data centers) and the thermal demands (of residential, commercial, service, industrial and power (especially CSP) sectors) is a key step. For instance, using waste materials where they are produced as STESMs will minimize the energy used for transportation and reduce the embedded $\mathrm{CO}_{2}$ of the source product. The awareness of how to exploit this potential among the key players (such as industry, policymakers) should be increased. Some generic TES concepts for integration into industrial processes have been prepared by IEA SHC [146]. By abiding to and evolving from concepts as such, TES and TESM developments should strive to find 
innovative ways to realize circularity for material and energy resource optimization while paving the way to attractive business cases.

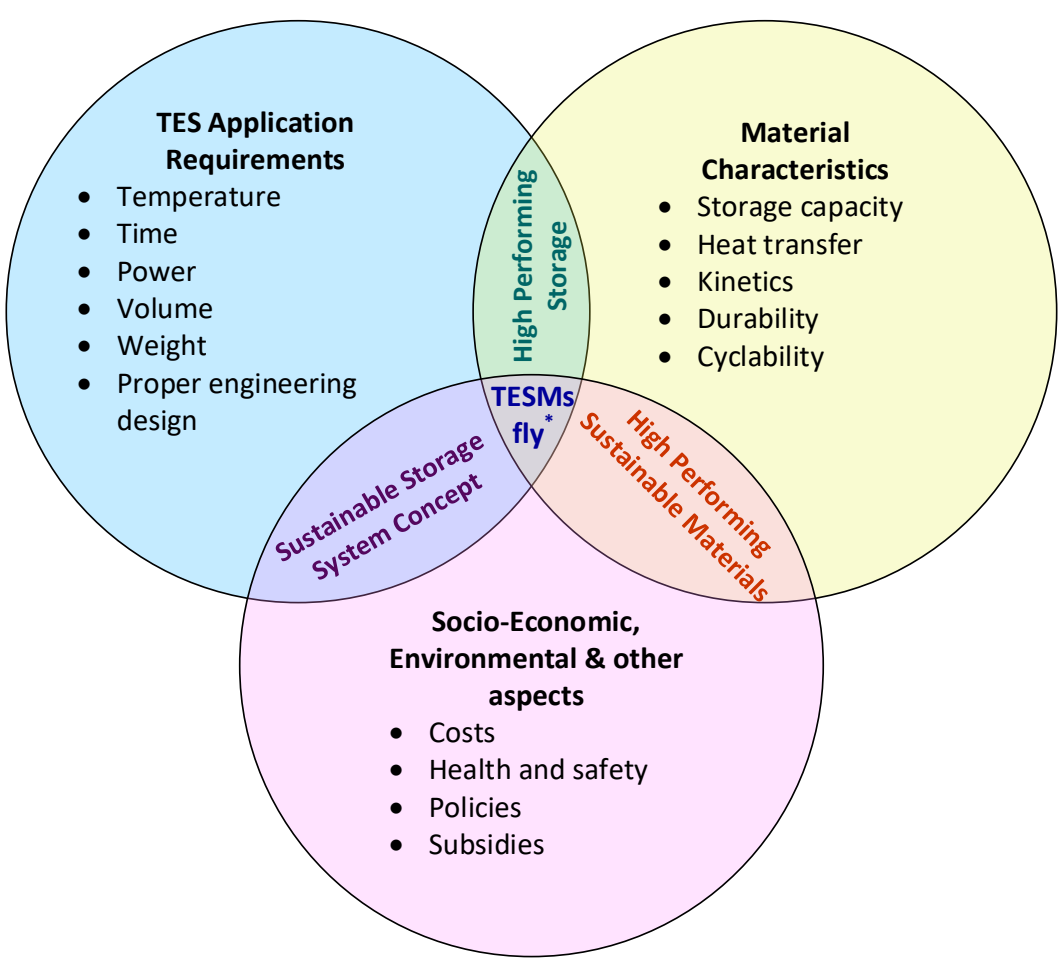

Figure 13. The ultimate goal. The key elements and synergies required to truly-enable TESMs to fly ${ }^{*}$ on the market by realizing high performing and sustainable TES with sustainable TESMs.

As a whole, TESMs have reached many corners in the market. STESMs have the most exposure on large-scale TES (in residential, commercial, and service-sector buildings as well as at industrial and power sectors). PCMs already appear in a versatile collection of small to medium-scale applications (from pharmaceuticals transportation insulation, currently experiencing a huge market surge with COVID-19 aftermath, and hand warmers, to even some indoor climate management). TCMs have also started their expansion beyond laboratory and pilot scales (e.g., mobile sorption storage and power-to-heat applications). Nevertheless, the large-scale TES implementation with especially PCMs and TCMs has a long journey ahead, to learn from today's successes to explore future innovations for attractive business cases. The many advantages of TESMs packaged into a plug-and-play TES battery must be clearly merited in these business cases, to be able to succeed. On top of the typical advantages in peak shaving, load shifting, efficiency improvements and emissions reductions, the strategic advantages of TES in energy systems have a deterministic role in its promotion and commercial success. Enabling flexible sector coupling via power-to-heat and power-to-cold adaptations to absorb intermittent renewable electricity thereby reducing their curtailment is one predominant strategic advantage of TES to be incorporated here. These services TES accommodates are already known (e.g., in power-to-heat with renewable and even nuclear power integration [2,147] and micro grids management [148]) although the broad dissemination, promotion, and widespread implementation synergizing all stakeholders is a journey ahead.

In conclusion, TES against other energy storage counterparts, or TESMs between each other (PCMs, TCMs or STESMs), must not be competitors but rather complements in a unified energy system. Holistic appraisal of the energy systems is a key ingredient to success where the battle should always be against climate change to realize our dream of a "carbon neutral future". 
Author Contributions: Conceptualization, S.N.G., C.B., A.I.F., R.R., A.R., P.W., H.Ö.P., C.R., J.N.C. and A.S.; Data curation, A.C.; Formal analysis, C.B., A.I.F. and A.C.; Investigation, S.N.G., C.B., A.I.F., R.R., A.R., P.W., H.Ö.P., B.K., C.R. and J.N.C.; Methodology, S.N.G., C.B., A.I.F., R.R., A.R., P.W., H.Ö.P., C.R. and J.N.C.; Software, A.C.; Visualization, A.C. and A.R.; Writing-original draft, S.N.G., C.B., A.I.F., R.R., A.R., P.W., H.Ö.P., B.K., C.R. and J.N.C.; Writing-review and editing, S.N.G., C.B., A.I.F., R.R., A.R., P.W., H.Ö.P., B.K., C.R., J.N.C. and A.S. All authors have read and agreed to the published version of the manuscript.

Funding: In this research collaboration, the work from: Sweden was funded by KTH Royal Institute of Technology, Sweden; from Spain was supported by the Spanish government RTI2018-093849-BC32 MCIU/AEI/FEDER, UE and PCI2020-120682-2 MCIU/AEI; from Slovenia was funded by the Slovenian Research Agency in the frame of the research program P1-0021 (Nanoporous materials); from Austria was supported by the Austrian Research Promotion Agency in the frame of the projects 841.150, 848.876 and 853.593; and from ZAE Bayern, Germany was part of the project properPCM and supported by the German Federal Ministry of Economic Affairs and Energy under the project code 03ET1342A. The collaboration work from Turkey was funded by Çukurova University as parts of the projects BAP Project [FDK-2018-9602], CSP-ERA-Net* 1st Cofund Joint Call by AEI, Spanish Ministry of Science, Innovation and Universities; TUBITAK, Scientific and Technological Research Council of Turkey (Project No: 120N663); and CSO, Israeli Ministry of Energy ( ${ }^{*}$ where CSP-ERA-Net is supported by the European Commission within the EU Framework Program for Research and Innovation HORIZON 2020 (Cofund ERA-NET Action, N 838311)).

Institutional Review Board Statement: Not applicable.

Informed Consent Statement: Not applicable.

Data Availability Statement: The data supporting the reported results on the bibliometric study can be provided upon request.

Acknowledgments: The authors acknowledge their individual research institutes for facilitating, and funding authorities for funding, the collaboration work in this paper. PW acknowledges financial support of the Austrian Research Promotion Agency (FFG) via projects 841150/848876/853593.

Conflicts of Interest: The authors declare no conflict of interest.

\section{Appendix A}

The summary of the keyword search string used in the bibliometric analysis is the following: (TS = (("thermal storage" AND "materials") OR ("thermal energy" AND "materials "AND ("storage")) OR ("cool storage "AND" materials" AND ("thermal")) OR ("concentrated solar power" AND "materials") OR ("phase change material") OR ("thermochemical storage "AND" materials") OR ("molten salts" AND ("solar" OR "energy" OR "power plant" OR " storage")) NOT ("PV" OR "photovoltaic") OR ("csp" AND "materials" AND ("solar" OR "energy" OR "renewable" OR "power" OR " storage")) NOT ("cloud" OR "internet" OR "software") OR ("heat storage" AND "materials") OR ("latent heat" AND "materials" AND ("storage")) OR ("sensible heat" AND "materials" AND ("storage")) OR ("thermochemical" AND "materials" AND ("energy storage")) OR ("PCM" AND ("energy storage")))).

\section{References}

1. REN21. Renewables 2020 Global Status Report; REN21 Secretariat; United Nations Environment Programme: Paris, France, 2020; Available online: http:/ / www.ren21.net/resources/publications/2 (accessed on 2 April 2021).

2. Bloess, A.; Schill, W.-P.; Zerrahn, A. Power-to-heat for renewable energy integration: A review of technologies, modeling approaches, and flexibility potentials. Appl. Energy 2018, 212, 1611-1626. [CrossRef]

3. Böttger, D.; Götz, M.; Lehr, N.; Kondziella, H.; Bruckner, T. Potential of the Power-to-Heat Technology in District Heating Grids in Germany. 8th International Renewable Energy Storage Conference and Exhibition, IRES 2014. Energy Procedia 2014, 46, $246-253$. [CrossRef]

4. WINDNODE. Balancing the power grid by generating heat and cold. In Balancing the Power Grid by Generating Heat and Cold; 2021. Available online: https://www.windnode.de/en/windnode-spotlight/heat-cold-power-grid/ (accessed on 12 April 2021).

5. IEA TCP ES Annex 35. IEA ES-Flexible Sector Coupling Annex 35. 2021. Available online: https://iea-eces.org/annex-35 (accessed on 22 March 2021). 
6. Gur, I.; Sawyer, K.; Prasher, R. Searching for a Better Thermal Battery. Science 2012, 335, 1454-1455. [CrossRef]

7. Mehling, H.; Cabeza, L.F. Heat and Cold Storage with PCM: An up to Date Introduction into Basics and Applications; Heat and Mass Transfer; Springer: Berlin/Heidelberg, Germany, 2008. [CrossRef]

8. Raoux, S. Phase Change Materials. Annu. Rev. Mater. Res. 2009, 39, 25-48. [CrossRef]

9. Almendros-Ibáñez, J.A.; Fernández-Torrijos, M.; Díaz-Heras, M.; Belmonte, J.F.; Sobrino, C. A review of solar thermal energy storage in beds of particles: Packed and fluidized beds. Sol. Energy 2019, 192, 193-237. [CrossRef]

10. Alva, G.; Liu, L.; Huang, X.; Fang, G. Thermal Energy Storage Materials and systems for solar energy applications. Renew. Sustain. Energy Rev. 2017, 68, 693-706. [CrossRef]

11. Koçak, B.; Paksoy, H. Using demolition wastes from urban regeneration as sensible thermal energy storage material. Int. J. Energy Res. 2019, 43, 6454-6460. [CrossRef]

12. Ravotti, R.; Worlitschek, J.; Pulham, C.R.; Stamatiou, A. Triglycerides as Novel Phase-Change Materials: A Review and Assessment of Their Thermal Properties. Molecules 2020, 25, 5572. [CrossRef]

13. Gunasekara, S.N.; Martin, V.; Chiu, J.N. Phase equilibrium in the design of phase change materials for thermal energy storage: State-of-the-art. Renew. Sustain. Energy Rev. 2017, 73, 558-581. [CrossRef]

14. Wu, H.; Salles, F.; Zajac, J. A Critical Review of Solid Materials for Low-Temperature Thermochemical Storage of Solar Energy Based on Solid-Vapour Adsorption in View of Space Heating Uses. Molecules 2019, 24, 945. [CrossRef]

15. Müller, D.; Knoll, C.; Gravogl, G.; Jordan, C.; Eitenberger, E.; Friedbacher, G.; Artner, W.; Welch, J.M.; Werner, A.; Harasek, M.; et al. Medium-temperature thermochemical energy storage with transition metal ammoniates-A systematic material comparison. Appl. Energy 2021, 285, 116470. [CrossRef]

16. Hauer, A.; Fischer, F.; Rathgeber, C. 4-Temperatures Approach: Testing Thermochemical Heat Storage Materials Under Application Conditions. Chem. Ing. Tech. 2021, 93, 618-623. [CrossRef]

17. Köll, R.; van Helden, W.; Engel, G.; Wagner, W.; Dang, B.; Jänchen, J.; Kerskes, H.; Badenhop, T.; Herzog, T. An experimental investigation of a realistic-scale seasonal solar adsorption storage system for buildings. Sol. Energy 2017, 155, 388-397. [CrossRef]

18. Mustapha, A.N.; Onyeaka, H.; Omoregbe, O.; Ding, Y.; Li, Y. Latent heat thermal energy storage: A bibliometric analysis explicating the paradigm from 2000-2019. J. Energy Storage 2021, 33, 102027. [CrossRef]

19. Gunasekara, S.N.; Chiu, J.N.; Martin, V.; Hedström, P. The experimental phase diagram study of the binary polyols system erythritol-xylitol. Sol. Energy Mater. Sol. Cells 2018, 174, 248-262. [CrossRef]

20. Gunasekara, S.N.; Ignatowicz, M.; Chiu, J.N.; Martin, V. Thermal conductivity measurement of erythritol, xylitol, and their blends for phase change material design: A methodological study. Int. J. Energy Res. 2019, 43, 1785-1801. [CrossRef]

21. Abdi, A.; Ignatowicz, M.; Gunasekara, S.N.; Chiu, J.N.; Martin, V. Experimental investigation of thermo-physical properties of n-octadecane and n-eicosane. Int. J. Heat Mass Transf. 2020, 161, 120285. [CrossRef]

22. Hauer, A.; Fumey, B.; Gschwander, S.; Lager, D.; Lázaro, A.; Rathgeber, C.; Ristić, A.; van Helden, W. IEA-ES-TCP-Annex33-Executive-Summary. 2020. Available online: https://iea-eces.org/wp-content/uploads/public/IEA-ES-TCP-Annex-33 -Executive-Summary_revised.pdf (accessed on 13 April 2021).

23. Simó-Solsona, M.; Palumbo, M.; Bosch, M.; Fernandez, A.I. Why it's so hard? Exploring social barriers for the deployment of thermal energy storage in Spanish buildings. Energy Res. Soc. Sci. 2021, 76, 102057. [CrossRef]

24. Müller, D.; Knoll, C.; Ruh, T.; Artner, W.; Welch, J.M.; Peterlik, H.; Eitenberger, E.; Friedbacher, G.; Harasek, M.; Blaha, P.; et al. Calcium Doping Facilitates Water Dissociation in Magnesium Oxide. Adv. Sustain. Syst. 2018, 2, 1700096. [CrossRef]

25. Gravogl, G.; Knoll, C.; Welch, J.; Artner, W.; Freiberger, N.; Nilica, R.; Eitenberger, E.; Friedbacher, G.; Harasek, M.; Werner, A.; et al. Cycle Stability and Hydration Behavior of Magnesium Oxide and Its Dependence on the Precursor-Related Particle Morphology. Nanomaterials 2018, 8, 795. [CrossRef]

26. Krajnc, A.; Varlec, J.; Mazaj, M.; Ristić, A.; Logar, N.Z.; Mali, G. Superior Performance of Microporous Aluminophosphate with LTA Topology in Solar-Energy Storage and Heat Reallocation. Adv. Energy Mater. 2017, 7, 1601815. [CrossRef]

27. Ristić, A.; Logar, N.Z.; Henninger, S.K.; Kaučič, V. The Performance of Small-Pore Microporous Aluminophosphates in LowTemperature Solar Energy Storage: The Structure-Property Relationship. Adv. Funct. Mater. 2012, 22, 1952-1957. [CrossRef]

28. Breck, D.W. Zeolite Molecular Sieves: Structure, Chemistry, and Use; Wiley: New York, NY, USA, 1973; ISBN 978-0-471-09985-7.

29. Müller, D.; Knoll, C.; Gravogl, G.; Artner, W.; Welch, J.M.; Eitenberger, E.; Friedbacher, G.; Schreiner, M.; Harasek, M.; Hradil, $\mathrm{K}$.; et al. Tuning the performance of $\mathrm{MgO}$ for thermochemical energy storage by dehydration-From fundamentals to phase impurities. Appl. Energy 2019, 253, 113562. [CrossRef]

30. Centre for Science and Technology Studies-Leiden University. In VOSviewer-Visualizing Scientific Landscape; VOSviewer, 2021; Available online: http:/ / www.vosviewer.com/ (accessed on 13 April 2021).

31. Complexity Lab Barcelona. Complexity Lab Barcelona-Home Page. Available online: http:/ / complex.ffn.ub.es (accessed on 17 March 2021).

32. Fernández, A.I.; Barreneche, C.; Miró, L.; Brückner, S.; Cabeza, L.F.; Fernández, A.I.; Barreneche, C.; Miró, L.; Cabeza, L.F.; Brückner, S. Waste heat recovery using thermal energy storage. In Advances in Thermal Energy Storage Systems; Elsevier: Amsterdam, The Netherlands, 2021; pp. 639-653. ISBN 978-0-12-819885-8.

33. Alnaimat, F.; Rashid, Y. Thermal Energy Storage in Solar Power Plants: A Review of the Materials, Associated Limitations, and Proposed Solutions. Energies 2019, 12, 4164. [CrossRef] 
34. Liu, M.; Steven Tay, N.H.; Bell, S.; Belusko, M.; Jacob, R.; Will, G.; Saman, W.; Bruno, F. Review on concentrating solar power plants and new developments in high temperature thermal energy storage technologies. Renew. Sustain. Energy Rev. 2016, 53, 1411-1432. [CrossRef]

35. Trevisan, S.; Guédez, R. Thermodynamic Analysis of a High-Temperature Multi-Layered Sensible-Latent Thermal Energy Storage. AIP Conf. Proc. 2020, 2303, 190030.

36. Trevisan, S. Literature Survey-Course MJ 3123; 3rd Cycle Course on Literature Survey; KTH Royal Institute of Technology, Department of Energy Technology: Stockholm, Sweden, 2021; p. 28.

37. Konuklu, Y.; Şahan, N.; Paksoy, H. 2.14 Latent Heat Storage Systems. In Comprehensive Energy Systems; Elsevier: Amsterdam, The Netherlands, 2018; pp. 396-434. ISBN 978-0-12-814925-6.

38. Lane, G.A. Solar Heat Storage: Latent Heat Material; CRC Press Inc.: Boca Raton, FL, USA, 1983; Volume 1.

39. Telkes, M. Thermal energy storage in salt hydrates. Sol. Energy Mater. 1980, 2, 381-393. [CrossRef]

40. Shahid, U.B.; Abdala, A. A critical review of phase change material composite performance through Figure-of-Merit analysis: Graphene vs. Boron Nitride. Energy Storage Mater. 2021, 34, 365-387. [CrossRef]

41. Whittingham, M.S. History, Evolution, and Future Status of Energy Storage. Proc. IEEE 2012, 100, 1518-1534. [CrossRef]

42. United Nations Climate Agreement. The Paris Agreement. 2021. Available online: https://unfccc.int/process-and-meetings/theparis-agreement/the-paris-agreement (accessed on 19 May 2021).

43. Abhat, A. Low temperature latent heat thermal energy storage: Heat storage materials. Sol. Energy 1983, 30, 313-332. [CrossRef]

44. Purohit, B.K.; Sistla, V.S. Inorganic salt hydrate for thermal energy storage application: A review. Energy Storage 2021, 3, e212. [CrossRef]

45. Jankowski, N.R.; McCluskey, F.P. A review of phase change materials for vehicle component thermal buffering. Appl. Energy 2014, 113, 1525-1561. [CrossRef]

46. Mandelcorn, L. Clathrates. Chem Rev. 1959, 59, 827-839. [CrossRef]

47. IEA ECES Annex 29 and SHC Task 42. Task 42-Annex 29 Thermal Material Database-Wiki PCM. 2021. Available online: https: / thermalmaterials.org/ (accessed on 10 February 2021).

48. Callister, W.D. Materials Science and Engineering: An Introduction, 7th ed.; John Wiley \& Sons: New York, NY, USA, 2007; ISBN 978-0-471-73696-7.

49. Gunasekara, S.N. Phase Equilibrium-aided Design of Phase Change Materials from Blends. Ph.D. Thesis, KTH Royal Institute of Technology, Stockholm, Sweden, 2017. Available online: http:/ / urn.kb.se/resolve?urn=urn:nbn:se:kth:diva-212440 (accessed on 18 February 2021).

50. Lane, G.A. Solar Heat Storage, Latent Heat Materials; CRC Press: Boca Baton, FL, USA, 1986; Volume 2, ISBN 978-1-315-89764-6.

51. Knoll, C.; Müller, D.; Artner, W.; Welch, J.M.; Werner, A.; Harasek, M.; Weinberger, P. Probing cycle stability and reversibility in thermochemical energy storage- $\mathrm{CaC}_{2} \mathrm{O}_{4} \cdot \mathrm{H}_{2} \mathrm{O}$ as perfect match? Appl. Energy 2017, 187, 1-9. [CrossRef]

52. Müller, D.; Knoll, C.; Gravogl, G.; Lager, D.; Welch, J.M.; Eitenberger, E.; Friedbacher, G.; Werner, A.; Artner, W.; Harasek, M.; et al. $\mathrm{CuSO}_{4} /\left[\mathrm{Cu}\left(\mathrm{NH}_{3}\right)_{4}\right] \mathrm{SO}_{4}$-Composite Thermochemical Energy Storage Materials. Nanomaterials 2020, 10, 2485. [CrossRef] [PubMed]

53. Gravogl, G.; Knoll, C.; Artner, W.; Eitenberger, E.; Friedbacher, G.; Werner, A.; Harasek, M.; Weinberger, P.; Müller, D.; Miletich, R. Moisture-triggered ambient-temperature carbonatization of main group II metal oxides under elevated $\mathrm{CO}_{2}$ pressure. In Proceedings of the SWC2017/SHC2017, International Solar Energy Society, Abu Dhabi, United Arab Emirates, 29 October-2 November 2017; pp. 1-12.

54. Gravogl, G.; Knoll, C.; Artner, W.; Welch, J.M.; Eitenberger, E.; Friedbacher, G.; Harasek, M.; Hradil, K.; Werner, A.; Weinberger, P.; et al. Pressure effects on the carbonation of $\mathrm{MeO}(\mathrm{Me}=\mathrm{Co}, \mathrm{Mn}, \mathrm{Pb}, \mathrm{Zn})$ for thermochemical energy storage. Appl. Energy 2019, 252, 113451. [CrossRef]

55. Gravogl, G.; Birkelbach, F.; Müller, D.; Lengauer, C.L.; Weinberger, P.; Miletich, R. Pressure Dependence of the Low Temperature Carbonation Kinetics of Calcium Oxide for Potential Thermochemical Energy Storage Purposes and Sustainable $\mathrm{CO}_{2}$ Fixation. Adv. Sustain. Syst. 2021, 5, 2100022. [CrossRef]

56. Knoll, C.; Müller, D.; Artner, W.; Welch, J.M.; Eitenberger, E.; Friedbacher, G.; Werner, A.; Weinberger, P.; Harasek, M. Magnesium oxide from natural magnesite samples as thermochemical energy storage material. Energy Procedia 2019, 158, 4861-4869. [CrossRef]

57. Muthukumar, P.; Groll, M. Metal hydride based heating and cooling systems: A review. Int. J. Hydrog. Energy 2010, 35, 3817-3831. [CrossRef]

58. Rönnebro, E.; Whyatt, G.; Powell, M.; Westman, M.; Zheng, F.; Fang, Z. Metal Hydrides for High-Temperature Power Generation. Energies 2015, 8, 8406-8430. [CrossRef]

59. Deutsch, M.; Horvath, F.; Knoll, C.; Lager, D.; Gierl-Mayer, C.; Weinberger, P.; Winter, F. High-Temperature Energy Storage: Kinetic Investigations of the $\mathrm{CuO} / \mathrm{Cu}_{2} \mathrm{O}$ Reaction Cycle. Energy Fuels 2017, 31, 2324-2334. [CrossRef]

60. Müller, D.; Knoll, C.; Artner, W.; Harasek, M.; Gierl-Mayer, C.; Welch, J.M.; Werner, A.; Weinberger, P. Combining in-situ X-ray diffraction with thermogravimetry and differential scanning calorimetry-An investigation of $\mathrm{Co}_{3} \mathrm{O}_{4}, \mathrm{MnO}_{2}$ and $\mathrm{PbO}_{2}$ for thermochemical energy storage. Sol. Energy 2017, 153, 11-24. [CrossRef]

61. Gunasekara, S.N.; Laios, M.; Karabanova, A.; Martin, V.; Blanchard, D. Design of a bench-scale ammonia-SrCl 2 thermochemical storage system using numerical modelling. In Eurotherm Seminar \#112-Advances in Thermal Energy Storage; Universitat de Lleida: Lleida, Spain, 2019; pp. 87-97. 
62. Deutsch, M.; Müller, D.; Aumeyr, C.; Jordan, C.; Gierl-Mayer, C.; Weinberger, P.; Winter, F.; Werner, A. Systematic search algorithm for potential thermochemical energy storage systems. Appl. Energy 2016, 183, 113-120. [CrossRef]

63. Hauer, A.; Fischer, F. Open Adsorption System for an Energy Efficient Dishwasher. Chem. Ing. Tech. 2011, 83, 61-66. [CrossRef]

64. Krönauer, A.; Lävemann, E.; Brückner, S.; Hauer, A. Mobile Sorption Heat Storage in Industrial Waste Heat Recovery. Energy Procedia 2015, 73, 272-280. [CrossRef]

65. Pinheiro, J.M.; Salústio, S.; Rocha, J.; Valente, A.A.; Silva, C.M. Adsorption heat pumps for heating applications. Renew. Sustain. Energy Rev. 2020, 119, 109528. [CrossRef]

66. RAL Quality Association PCM. Phase Change Materials, Phase Change Materials. 2021. Available online: https://www.pcm-ral. $\mathrm{org} / \mathrm{pcm} / \mathrm{en} /$ (accessed on 29 August 2021).

67. Mohan, G.; Venkataraman, M.; Gomez-Vidal, J.; Coventry, J. Thermo-economic analysis of high-temperature sensible thermal storage with different ternary eutectic alkali and alkaline earth metal chlorides. Sol. Energy 2018, 176, 350-357. [CrossRef]

68. John, E.; Hale, M.; Selvam, P. Concrete as a thermal energy storage medium for thermocline solar energy storage systems. Sol. Energy 2013, 96, 194-204. [CrossRef]

69. Navarro, M.E.; Martínez, M.; Gil, A.; Fernández, A.I.; Cabeza, L.F.; Olives, R.; Py, X. Selection and characterization of recycled materials for sensible thermal energy storage. Sol. Energy Mater. Sol. Cells 2012, 107, 131-135. [CrossRef]

70. Faik, A.; Guillot, S.; Lambert, J.; Véron, E.; Ory, S.; Bessada, C.; Echegut, P.; Py, X. Thermal storage material from inertized wastes: Evolution of structural and radiative properties with temperature. Sol. Energy 2012, 86, 139-146. [CrossRef]

71. Motte, F.; Falcoz, Q.; Veron, E.; Py, X. Compatibility tests between Solar Salt and thermal storage ceramics from inorganic industrial wastes. Appl. Energy 2015, 155, 14-22. [CrossRef]

72. Ozger, O.B.; Girardi, F.; Giannuzzi, G.M.; Salomoni, V.A.; Majorana, C.E.; Fambri, L.; Baldassino, N.; Di Maggio, R. Effect of nylon fibres on mechanical and thermal properties of hardened concrete for energy storage systems. Mater. Des. 2013, 51, 989-997. [CrossRef]

73. Agalit, H.; Zari, N.; Maaroufi, M. Thermophysical and chemical characterization of induction furnace slags for high temperature thermal energy storage in solar tower plants. Sol. Energy Mater. Sol. Cells 2017, 172, 168-176. [CrossRef]

74. Ortega-Fernández, I.; Calvet, N.; Gil, A.; Rodríguez-Aseguinolaza, J.; Faik, A.; D’Aguanno, B. Thermophysical characterization of a by-product from the steel industry to be used as a sustainable and low-cost thermal energy storage material. Energy 2015, 89, 601-609. [CrossRef]

75. Gil, A.; Medrano, M.; Martorell, I.; Lázaro, A.; Dolado, P.; Zalba, B.; Cabeza, L.F. State of the art on high temperature thermal energy storage for power generation. Part 1-Concepts, materials and modellization. Renew. Sustain. Energy Rev. 2010, 14, 31-55. [CrossRef]

76. Wei, G.; Wang, G.; Xu, C.; Ju, X.; Xing, L.; Du, X.; Yang, Y. Selection principles and thermophysical properties of high temperature phase change materials for thermal energy storage: A review. Renew. Sustain. Energy Rev. 2018, 81, 1771-1786. [CrossRef]

77. Alva, G.; Lin, Y.; Fang, G. An overview of thermal energy storage systems. Energy 2018, 144, 341-378. [CrossRef]

78. Kenisarin, M.; Mahkamov, K. Salt hydrates as latent heat storage materials:Thermophysical properties and costs. Sol. Energy Mater. Sol. Cells 2016, 145, 255-286. [CrossRef]

79. Rubitherm Technologies GmbH. PCM RT SERIES. 2021. Available online: https://www.rubitherm.eu/index.php/ produktkategorie/organische-pcm-rt (accessed on 20 July 2021).

80. Oliver, D.E.; Bissell, A.J.; Liu, X.; Tang, C.C.; Pulham, C.R. Crystallisation studies of sodium acetate trihydrate-suppression of incongruent melting and sub-cooling to produce a reliable, high-performance phase-change material. Cryst. Eng. Comm. 2021, 23, 700-706. [CrossRef]

81. Sunamp Ltd. Sunamp, World-Leading Thermal Storage Technologies. 2021. Available online: https://sunamp.com/ (accessed on 20 July 2021).

82. Pluss Advanced Technologies. PLUSS-Technology for a Better World; Pluss Advanced Technologies: Gurugram, India, 2021; Available online: https:/ / www.pluss.co.in/index.php (accessed on 20 July 2021).

83. Swerod, A.B. Swerod-Moving Energy in Time, Energy Storage on a New Level -Capture Free Energy and Use It When Needed. 2021. Available online: http:/ / www.swerod.com/en/ (accessed on 20 July 2021).

84. Gunasekara, S.N.; Kumova, S.; Chiu, J.N.; Martin, V. Experimental phase diagram of the dodecane-tridecane system as phase change material in cold storage. Int. J. Refrig. 2017, 82, 130-140. [CrossRef]

85. Noël, J.A.; Allred, P.M.; White, M.A. Life cycle assessment of two biologically produced phase change materials and their related products. Int. J. Life Cycle Assess. 2015, 20, 367-376. [CrossRef]

86. Lizana, J.; Chacartegui, R.; Barrios-Padura, A.; Valverde, J.M.; Ortiz, C. Identification of best available thermal energy storage compounds for low-to-moderate temperature storage applications in buildings. Mater. Constr. 2018, 68, 160. [CrossRef]

87. Noël, J.A.; Kreplak, L.; Getangama, N.N.; de Bruyn, J.R.; White, M.A. Supercooling and Nucleation of Fatty Acids: Influence of Thermal History on the Behavior of the Liquid Phase. J. Phys. Chem. B 2018, 122, 12386-12395. [CrossRef] [PubMed]

88. Riemenschneider, W.; Bolt, H.M. Esters, Organic. In Ullmann's Encyclopedia of Industrial Chemistry; Wiley-VCH Verlag GmbH \& Co. KGaA: Weinheim, Germany, 2005; ISBN 978-3-527-30673-2.

89. Stamatiou, A.; Obermeyer, M.; Fischer, L.J.; Schuetz, P.; Worlitschek, J. Investigation of unbranched, saturated, carboxylic esters as phase change materials. Renew. Energy 2017, 108, 401-409. [CrossRef] 
90. Ravotti, R.; Fellmann, O.; Lardon, N.; Fischer, L.; Stamatiou, A.; Worlitschek, J. Investigation of Lactones as Innovative Bio-Sourced Phase Change Materials for Latent Heat Storage. Molecules 2019, 24, 1300. [CrossRef]

91. Ravotti, R.; Fellmann, O.; Lardon, N.; Fischer, L.; Stamatiou, A.; Worlitschek, J. Synthesis and Investigation of Thermal Properties of Highly Pure Carboxylic Fatty Esters to Be Used as PCM. Appl. Sci. 2018, 8, 1069. [CrossRef]

92. Ravotti, R.; Fellmann, O.; Lardon, N.; Fischer, L.; Stamatiou, A.; Worlitschek, J. Analysis of Bio-Based Fatty Esters PCM's Thermal Properties and Investigation of Trends in Relation to Chemical Structures. Appl. Sci. 2019, 9, 225. [CrossRef]

93. Ravotti, R.; Fellmann, O.; Fischer, L.J.; Worlitschek, J.; Stamatiou, A. Investigation of the Thermal Properties of Diesters from Methanol, 1-Pentanol, and 1-Decanol as Sustainable Phase Change Materials. Materials 2020, 13, 810. [CrossRef]

94. Burke, R.A. Hazardous Materials Chemistry for Emergency Responders, 3rd ed.; CRC Press: New York, NY, USA, 2013; ISBN 13: 978-1-4398-4986-6.

95. Schmidt, B.; Buddrus, J. Grundlagen der Organischen Chemie; De Gruyter Studium: Berlin/München, Germany; Boston, MA, USA, 2009; ISBN 978-3-11-030559-3. Available online: http:/ / scripts.iucr.org/cgi-bin/paper?S0108768109046060 (accessed on 7 May 2021).

96. Alper Aydın, A. High-chain fatty acid esters of 1-octadecanol as novel organic phase change materials and mathematical correlations for estimating the thermal properties of higher fatty acid esters' homologous series. Sol. Energy Mater. Sol. Cells 2013, 113, 44-51. [CrossRef]

97. Gunasekara, S.N.; Pan, R.; Chiu, J.N.; Martin, V. Polyols as phase change materials for surplus thermal energy storage. Appl. Energy 2016, 162, 1439-1452. [CrossRef]

98. Croda International Plc. CRODA-Smart Science to improve lives. Product Finder. 2021. Available online: https://www. crodaenergytechnologies.com/en-gb / product-finder?currentPage=1\&pageSize=20\&sortBy=recommended\&lang=en-gb (accessed on 20 July 2021).

99. Gunasekara, S.N.; Stalin, J.; Marçal, M.; Delubac, R.; Karabanova, A.; Wei Chiu, J.N.; Martin, V. Erythritol, glycerol, their blends, and olive oil, as sustainable phase change materials. Energy Procedia 2017, 135, 249-262. [CrossRef]

100. Gordeeva, L.G.; Aristov, Y.I. Composites 'salt inside porous matrix' for adsorption heat transformation: A current state-of-the-art and new trends. Int. J. Low-Carbon Technol. 2012, 7, 288-302. [CrossRef]

101. Ristić, A.; Logar, N.Z. New Composite Water Sorbents CaCl2-PHTS for Low-Temperature Sorption Heat Storage: Determination of Structural Properties. Nanomaterials 2018, 9, 27. [CrossRef] [PubMed]

102. Permyakova, A.; Wang, S.; Courbon, E.; Nouar, F.; Heymans, N.; D’Ans, P.; Barrier, N.; Billemont, P.; De Weireld, G.; Steunou, N.; et al. Design of salt-metal organic framework composites for seasonal heat storage applications. J. Mater. Chem. A 2017, 5, 12889-12898. [CrossRef]

103. Calabrese, L.; Brancato, V.; Palomba, V.; Frazzica, A.; Cabeza, L.F. Magnesium sulphate-silicone foam composites for thermochemical energy storage: Assessment of dehydration behaviour and mechanical stability. Sol. Energy Mater. Sol. Cells 2019, 200, 109992. [CrossRef]

104. Ristić, A.; Maučec, D.; Henninger, S.K.; Kaučič, V. New two-component water sorbent CaCl2-FeKIL2 for solar thermal energy storage. Microporous Mesoporous Mater. 2012, 164, 266-272. [CrossRef]

105. Jänchen, J.; Schumann, K.; Thrun, E.; Brandt, A.; Unger, B.; Hellwig, U. Preparation, hydrothermal stability and thermal adsorption storage properties of binderless zeolite beads. Int. J. Low-Carbon Technol. 2012, 7, 275-279. [CrossRef]

106. Fischer, F.; Lutz, W.; Buhl, J.-C.; Laevemann, E. Insights into the hydrothermal stability of zeolite 13X. Microporous Mesoporous Mater. 2018, 262, 258-268. [CrossRef]

107. Ristić, A.; Fischer, F.; Hauer, A.; Zabukovec Logar, N. Improved performance of binder-free zeolite Y for low-temperature sorption heat storage. J. Mater. Chem. A 2018, 6, 11521-11530. [CrossRef]

108. Brancato, V.; Frazzica, A. Characterisation and comparative analysis of zeotype water adsorbents for heat transformation applications. Sol. Energy Mater. Sol. Cells 2018, 180, 91-102. [CrossRef]

109. Henninger, S.K.; Munz, G.; Ratzsch, K.-F.; Schossig, P. Cycle stability of sorption materials and composites for the use in heat pumps and cooling machines. Renew. Energy 2011, 36, 3043-3049. [CrossRef]

110. Henninger, S.K.; Jeremias, F.; Kummer, H.; Janiak, C. MOFs for Use in Adsorption Heat Pump Processes. Eur. J. Inorg. Chem. 2012, 2012, 2625-2634. [CrossRef]

111. Chen, B.; Kuznik, F.; Horgnies, M.; Johannes, K.; Morin, V.; Gengembre, E. Physicochemical properties of ettringite/meta-ettringite for thermal energy storage: Review. Sol. Energy Mater. Sol. Cells 2019, 193, 320-334. [CrossRef]

112. SaltX Technology Holding AB. SaltX Technology-Energy Storage with Nano Coated Salt. The Shift to a Sustainable Future is Now Possible-Industrial Scale Energy Storage Green-Clean-Safe. 2021. Available online: https:/ / saltxtechnology.com/ (accessed on 20 July 2021).

113. Harasek, M.; Werner, A.; Weinberger, P. SolidHeat; TheoCryst. TU Wien, Institut für Angewandte Synthesechemie: Vienna, Austria, 2015.

114. Müller, D.; Knoll, C.; Gravogl, G.; Werner, A.; Harasek, M.; Miletich, R.; Weinberger, P. Lab-scale demonstration of thermochemical energy storage with $\mathrm{NH}_{3}$ and impregnated-loaded zeolites. In Proceedings of the SWC2017/SHC2017; International Solar Energy Society, Abu Dhabi, United Arab Emirates, 29 October-2 November 2017; pp. 1-9.

115. Müller, D.; Knoll, C.; Gravogl, G.; Artner, W.; Werner, A.; Welch, J.M.; Harasek, M.; Miletich, R.; Weinberger, P. Low-temperature carbonatization of metal oxides. Energy Procedia 2019, 158, 4870-4881. [CrossRef] 
116. Zhao, C.Y.; Tao, Y.B.; Yu, Y.S. Molecular dynamics simulation of nanoparticle effect on melting enthalpy of paraffin phase change material. Int. J. Heat Mass Transf. 2020, 150, 119382. [CrossRef]

117. Zhang, Z.; Li, W.; Zhang, W.; Huang, X.; Ruan, L.; Wu, L. Experimental, quantum chemical calculations and molecular dynamics (MD) simulation studies of methionine and valine as corrosion inhibitors on carbon steel in phase change materials (PCMs) solution. J. Mol. Liq. 2018, 272, 528-538. [CrossRef]

118. Zhao, C.Y.; Tao, Y.B.; Yu, Y.S. Molecular dynamics simulation of thermal and phonon transport characteristics of nanocomposite phase change material. J. Mol. Liq. 2021, 329, 115448. [CrossRef]

119. Zhang, M.; Wang, C.; Luo, A.; Liu, Z.; Zhang, X. Molecular dynamics simulation on thermophysics of paraffin/EVA/graphene nanocomposites as phase change materials. Appl. Therm. Eng. 2020, 166, 114639. [CrossRef]

120. Liu, X.; Rao, Z. Molecular dynamics simulations on the heat and mass transfer of hypercrosslinked shell structure of phase change nanocapsules as Thermal Energy Storage Materials. Int. J. Heat Mass Transf. 2019, 132, 362-374. [CrossRef]

121. Yu, Y.; Tao, Y.; He, Y.-L. Molecular dynamics simulation of thermophysical properties of NaCl-SiO2 based molten salt composite phase change materials. Appl. Therm. Eng. 2020, 166, 114628. [CrossRef]

122. Göbel, A.; Vidi, S.; Klinker, F.; Hemberger, F.; Brütting, M.; Ebert, H.-P.; Mehling, H. Method for the Thermal Characterization of PCM Systems in the Volume Range from $100 \mathrm{~mL}$ to $1000 \mathrm{~mL}$. Int. J. Thermophys. 2017, 38, 67. [CrossRef]

123. Cabeza, L.F.; Barreneche, C.; Martorell, I.; Miró, L.; Sari-Bey, S.; Fois, M.; Paksoy, H.O.; Sahan, N.; Weber, R.; Constantinescu, M.; et al. Unconventional experimental technologies available for phase change materials (PCM) characterization. Part 1. Thermophysical properties. Renew. Sustain. Energy Rev. 2015, 43, 1399-1414. [CrossRef]

124. Majó, M.; Sánchez, R.; Barcelona, P.; García, J.; Fernández, A.I.; Barreneche, C. Degradation of Fatty Acid Phase-Change Materials (PCM): New Approach for Its Characterization. Molecules 2021, 26, 982. [CrossRef]

125. Lovelyn Theresa, I.; Velraj, R. Thermophysical characterization and comparison of PCMs using DSC and T-History experimental setup. Mater. Res. Express 2019, 6, 125527. [CrossRef]

126. Nkhonjera, L.; Bello-Ochende, T.; John, G.; King'ondu, C.K. A review of thermal energy storage designs, heat storage materials and cooking performance of solar cookers with heat storage. Renew. Sustain. Energy Rev. 2017, 75, 157-167. [CrossRef]

127. Paksoy, H.Ö. (Ed.) Thermal Energy Storage for Sustainable Energy Consumption; NATO Science Series; Springer: Dordrecht, The Netherlands, 2007; Volume 234, ISBN 978-1-4020-5288-0.

128. Nie, B.; Zou, B.; She, X.; Zhang, T.; Li, Y.; Ding, Y. Development of a heat transfer coefficient based design method of a thermal energy storage device for transport air-conditioning applications. Energy 2020, 196, 117083. [CrossRef]

129. Duraković, B. PCM-Based Building Envelope Systems-Innovative Energy Solutions for Passive Design; Faculty of Engineering and Natural Sciences, International University of Sarajevo Sarajevo: Ilidža, Bosnia and Herzegovina, 2020.

130. Beaupere, N.; Soupremanien, U.; Zalewski, L. Nucleation triggering methods in supercooled phase change materials (PCM), a review. Thermochim. Acta 2018, 670, 184-201. [CrossRef]

131. Lee, A.Y.; Erdemir, D.; Myerson, A.S. Crystal Polymorphism in Chemical Process Development. Annu. Rev. Chem. Biomol. Eng. 2011, 2, 259-280. [CrossRef]

132. Cruz-Cabeza, A.J.; Feeder, N.; Davey, R.J. Open questions in organic crystal polymorphism. Commun. Chem. 2020, 3, 142. [CrossRef]

133. Kumar, N.; Hirschey, J.; LaClair, T.J.; Gluesenkamp, K.R.; Graham, S. Review of stability and thermal conductivity enhancements for salt hydrates. J. Energy Storage 2019, 24, 100794. [CrossRef]

134. Rathgeber, C.; Hiebler, S.; Bayón, R.; Cabeza, L.F.; Zsembinszki, G.; Englmair, G.; Dannemand, M.; Diarce, G.; Fellmann, O.; Ravotti, R.; et al. Experimental Devices to Investigate the Long-Term Stability of Phase Change Materials under Application Conditions. Appl. Sci. 2020, 10, 7968. [CrossRef]

135. $\mathrm{Xu}, \mathrm{T}$. Integrating Latent Heat Storage into Residential Heating Systems-A Study from Material and Component Characterization to System Analysis. PhD Thesis, KTH Royal Institute of Technology, Stockholm, Sweden, 2021. Available online: https://kth.diva-portal.org/smash/record.jsf?dswid=-9366\&pid=diva2\%3A1548439\&c=1\&searchType=SIMPLE\& language $=$ en \&query $=$ tianhao $+\mathrm{xu} \& \mathrm{af}=\% 5 \mathrm{~B} \% 22$ publicationTypeCode $\% 3$ AcomprehensiveDoctoralThesis $\% 22 \% 5 \mathrm{D} \& \mathrm{aq}=\% 5 \mathrm{~B} \%$ 5B $\% 5 \mathrm{D} \% 5 \mathrm{D} \&$ aq2 $=\% 5 \mathrm{~B} \% 5 \mathrm{~B} \% 5 \mathrm{D} \% 5 \mathrm{D} \& \mathrm{aqe}=\% 5 \mathrm{~B} \% 5 \mathrm{D} \&$ noOfRows=50\&sortOrder=author_sort_asc\&sortOrder2=title_sort_asc\& onlyFullText=false\&sf=all (accessed on 30 May 2021).

136. Huggins, R. Energy Storage, 2nd ed.; Springer International Publishing: Stanford, CA, USA, 2016; ISBN 978-3-319-21238-8.

137. IEA SHC. IEA Solar Heating \& Cooling Technology Collaboration Programme. 2021. Available online: https://www.iea-shc.org/ (accessed on 19 August 2021).

138. IEA ECES. IEA-Technology Collaboration Program-Energy Conservation through Energy Storage. 2021. Available online: https: / / iea-eces.org/ (accessed on 19 August 2021).

139. IEA DHC. International Energy Agency Technology Collaboration Programme On District Heating And Cooling. 2021. Available online: https:/ / www.iea-dhc.org/home (accessed on 19 August 2021).

140. IRENA. IRENA-International Renewable Energy Agency. 2020. Available online: https://www.irena.org/ (accessed on 19 August 2021).

141. Guion, J.; Teisseire, M. Nucleation of sodium acetate trihydrate in thermal heat storage cycles. Sol. Energy 1991, 46, 97-100. [CrossRef] 
142. Massobrio, C.; Du, J.; Bernasconi, M.; Salmon, P.S. (Eds.) Molecular Dynamics Simulations of Disordered Materials; Springer Series in Materials Science; Springer International Publishing: Cham, Switzerland; Berlin/Heidelberg, Germany, 2015; Volume 215, ISBN 978-3-319-15674-3.

143. Kalikka, J.; Akola, J.; Jones, R.O. Crystallization processes in the phase change material $\mathrm{Ge}_{2} \mathrm{Sb}_{2} \mathrm{Te}_{5}$ : Unbiased density functional/molecular dynamics simulations. Phys. Rev. B 2016, 94, 134105. [CrossRef]

144. Kalaiselvam, S.; Parameshwaran, R. Thermal Energy Storage Technologies for Sustainability-Systems Design, Assessment and Applications, 1st ed.; Elsevier: Amsterdam, The Netherlands, 2014; ISBN 978-0-12-417291-3.

145. Chiu, J.N.-W. Latent Heat Thermal Energy Storage for Indoor Comfort Control. Ph.D. Thesis, KTH Royal Institute of Technology, Stockholm, Sweden, 2013.

146. Hassine, I.B.; Helmke, A.; Heß, S.; Krummenacher, P.; Muster, B.; Schmitt, B.; Schnitzer, H. Solar Process Heat for Production and Advanced Applications-Integration Guideline (Deliverable B2). 2015. Available online: http://task49.iea-shc.org/data/sites/1/ publications/150218_IEA\%20Task\%2049_D_B2_Integration_Guideline-final1.pdf (accessed on 23 August 2021).

147. Denholm, P.; Jeffrey, C.K.; Kutcher, C.F.; Paul, P.H. Wilson Decarbonizing the electric sector Combining renewable and nuclear energy using thermal storage. Energy Policy 2012, 44, 301-311. [CrossRef]

148. Yan, M.; Wang, D.; Lai, C.S.; Lai, L.L. A Review on Thermal Energy Modelling for Optimal Microgrids Management. Thermo 2021, 1, 63-76. [CrossRef] 